\title{
EVOLUCIÓN Y DISTRIBUCIÓN TERRITORIAL DE LOS TRABAJADORES EVENTUALES AGRARIOS SUBSIDIADOS EN ANDALUCÍA
}

\author{
Eugenio Cejudo García \\ Francisco Navarro Valverde \\ José Antonio Cañete Pérez \\ Departamento de Geografía Humana. Universidad de Granada \\ cejudo@ugr.es, favalver@ugr.es, joseaca@ugr.es
}

\section{RESUMEN}

El Subsidio de Desempleo Agrario (SDA) y la Renta Agraria (RA) poseen unas evidentes implicaciones geográficas al propiciar el mantenimiento del tejido poblacional y social de los espacios rurales andaluces, sobre todo en ese rural con desempleo estructural. La casi exacta coincidencia con la distribución de los afiliados a la seguridad social agraria, su concentración espacial a lo largo del tiempo, y la feminización-envejecimiento de su colectivo, posee una serie de consecuencias territoriales complejas: directas e indirectas, positivas (sostenimiento demográfico y poblacional de gran parte de los ámbitos rurales del interior andaluz, contribución a la conservación del paisaje y el patrimonio rural, como principales), pero también negativas (mantenimiento del círculo vicioso del desempleo estructural, dualidad del sector agrario y del territorio andaluz, sometimiento femenino, y apenas incidencia en las tasas reproductivas por ser mayoritariamente un colectivo de edad adulta avanzada, también como esenciales).

Palabras clave: subsidio agrario; desempleo agrario; mercado de trabajo; política territorial; Andalucía.

Fecha de recepción: noviembre 2014.

Fecha de aceptación: julio 2015. 


\section{ABSTRACT}

The Agricultural Unemployment Subsidy (AUS) has an obvious geographical implications, promoting the maintenance of population and social structure of rural areas in Andalusia, especially in the deep rural with a structural unemployment. The high overlap with the distribution of the members of the agrarian social security, its spatial concentration along time, and the feminization-aging of this collective, has several consequences: direct and indirect, positive (demographic and population maintenance of many of the inland rural areas, contribution to the conservation of the landscape and heritage), but also negative (keeping the vicious circle of structural unemployment, dualism in agriculture and andalusian region, female submission, and a little effect on reproductive rates because our collective is mainly of advanced age).

Keywords: agricultural unemployment subsidy; agricultural unemployment; labor market; territorial policy; Andalusia.

\section{ESTADO DE LA CUESTIÓN, OBJETIVOS Y FUENTES}

Abordar el tema de las prestaciones por desempleo que perciben los trabajadores eventuales agrarios subsidiados (TEAS a partir de ahora) que se establecieron en Andalucía y Extremadura no se puede hacer sin retrotraernos, cuanto menos, a la situación socioeconómica que vivían estos territorios tras el proceso de transición democrática; a la desigual incidencia regional de la desagrarización en base, fundamentalmente, a la estructura de la propiedad de la tierra; a los sistemas de cultivo y de explotación de la tierra o al vaciamiento que éstos sufren tras el éxodo rural. Aspectos todos ellos que confluyen en un mercado de trabajo agrario precario, eventual, con altísimas tasas de paro y fuertes diferencias territoriales, siendo Andalucía y Extremadura las CC.AA. más afectadas. Es, por tanto, en un contexto de necesidad social en el que se enmarca, en primer lugar, la protección por desempleo del colectivo de trabajadores eventuales agrarios.

Pero, además, su implantación, terminó por propiciar el alejamiento del jornalero andaluz de dos de sus señas de identidad básicas hasta ese momento: la lucha por la tierra como reivindicación histórica y el abandono de la cultura del trabajo frente a la «limosna del subsidio». Los Pactos de la Moncloa, a fin de evitar conflictos sociales y políticos con las fuerzas del régimen anterior y favorecer la consolidación de un estado democrático social y de derecho, convirtieron en excepcional cualquier medida que atentara contra la propiedad privada de los medios de producción y la libre empresa a la vez que implantó un modelo de colaboración interclasista del cual ellos fueron su plasmación.

En tercer lugar, la protección por desempleo que supone el subsidio de desempleo agrario (SDA a partir de ahora) y la renta agraria (RA a partir de ahora) ha venido siendo considerada, tal y como señala Romero (2009: 597-607), de forma mayoritaria, más como una dádiva que como un derecho al que accede un trabajador tras cumplir con los requisitos que la Administración, a través de la Seguridad Social, establece para el cobro de tal prestación dentro del Régimen Especial Agrario de la S.S (REASS), diferente del General, claramente desfavorecedor en prestaciones y coberturas así como en los devengos por ellas percibidos y que se ha mantenido hasta 2012. 
Finalmente, al amparo de los mecanismos de «fraude»-existentes por otra parte- en el cobro del SDA se ha trasladado una imagen absolutamente falsa de Andalucía y Extremadura hasta alcanzar el mito de «tierra subsidiada», especialmente de la mano de políticos al fragor de campañas electorales. Tal consideración es, citando a Anula y Díaz (1997), radicalmente falsa porque los beneficiarios de subsidios son muchos, están en todos los sectores económicos y se encuentran repartidos por todo el territorio nacional e internacional. Sin ánimo de extendernos, ¿cómo hay que llamar hoy en día a los que cobran a través del régimen de pago único en la Unión Europea unas cantidades desorbitadas -en relación con las del Subsidiopor el simple hecho de haber tenido el privilegio en su día de recibir ayudas a la producción ligadas a la Política Agrícola Común?

Más allá de estas consideraciones en las que enmarcar las prestaciones por desempleo agrario que se perciben en estas dos regiones españolas, estamos ante un fenómeno transversal, social, agrario, y por tanto, rural, que ha conllevado importantes repercusiones poblacionales y territoriales: freno del éxodo rural, por consiguiente, fijación de mujeres y jóvenes, mantenimiento de las pirámides demográficas, pervivencia de una adecuada estructura de asentamientos y sistema de ciudades en el agro andaluz,... Ya desde su creación a comienzos de la década de los 80 su necesidad se fundamentaba en auxiliar a un excedente de población agraria que padecía una problemática de desempleo estructural, e incluso, de precariedad económica. Esta pobreza agraria, era y es, consecuentemente rural, por lo que esa incidencia geográfica era y es palpable. Pero también implícitamente se perseguía, como objetivo obligado por parte de la Administración, el tratar de fijar población y mantener los espacios rurales andaluces y extremeños con un tejido social y económico adecuado. Era necesario ayudar a crear las condiciones sociales mínimas para los espacios rurales del Sur de España en un contexto en el que los flujos migratorios tanto nacionales como internacionales se encontraban cerrados tras la crisis de los años 70 y teniendo presente también el proceso de reconversión industrial y crisis económica que sufría nuestro país a mediados de los años 80 . Por tanto, este mecanismo ha favorecido al mantenimiento de la población en el mundo rural andaluz, contribuyendo a una mayor coherencia y articulación territorial.

Existe una abundante bibliografía dónde se estudia el SDA y la RA en Andalucía y Extremadura desde diferentes aspectos así como desde perspectivas y enfoques metodológicos dispares.

En efecto, el SDA ha sido tratado como manifestación necesaria de la denominada cuestión agraria en Andalucía y Extremadura -nunca resuelta por la históricamente demandada reforma agraria- desde la que se planteaban las tres dimensiones básicas asociadas a una estructura de la propiedad de la tierra desequilibrada e injusta socialmente; a saber, la dimensión productiva, la social y la política. Cuestión superada en nuestro país pero que, como señalan Arnalte, Baptista y Garrabou (2012: 16) «se encuentra lejos de estar cerrada ni circunscrita a los libros de historia» en la medida en que frente a los planteamientos clásicos se imponen otros que reflejan los conflictos hoy vigentes. Entre ellos la dimensión ambiental con lecturas diferenciadas entre países desarrollados y en desarrollo; o la misma dimensión social reflejada en la pobreza rural asociadas a la propiedad de la tierra en grandes partes del planeta sin olvidar la dimensión internacional de la tierra reflejada en la inmensa oleada de acaparamiento de tierras que afecta a países en desarrollo. En este contexto, como demostraron Naredo (1971), Martínez Alier (1978) o Sumpsi (1980), la agricultura andaluza, que 
tenía un comportamiento abiertamente capitalista desde mediados del siglo XIX, sufrió un fuerte proceso de modernización obligado por las condiciones que el propio sistema impone a partir de la década de los 50. Ello porque, como señala Delgado (1983: 23), la máxima rentabilidad económica se consigue, no cuando se hacen máximos los rendimientos sino cuando se obtiene el máximo beneficio con el menor riesgo. En este sentido, nos encontramos con trabajos en los que se analizan el SDA dentro del marco de las políticas públicas «desmovilizadoras» del movimiento jornalero así como rupturistas de sus señas identitarias: el acceso a la propiedad de la tierra y el trabajo y el sudor como diferenciador del «señorito» andaluz (Palenzuela, 1989; Moreno, 1992; Talego, 2012).

Pero, sin lugar a dudas, es desde la perspectiva del mercado de trabajo agrario desde donde más se ha publicado sobre el necesario papel social desempeñado por el SDA. Mercado de trabajo definido como «profundamente segmentado», caracterizado por un monopolio de la oferta de trabajo por el sector social detentador de la propiedad de la tierra; un excedente estructural de mano de obra que permite atender a la demanda en períodos concretos; fuerte eventualidad y estacionalidad en el trabajo; poca o nula cualificación de la mayor parte del contingente de asalariados agrícolas; bajo nivel de retribución salarial, lo que genera una perenne situación de precariedad en la economía doméstica; débil representación sindical y permanente situación de complementariedad (Gavira, 1992; Baigorri, 1994; Delgado y Gavira, 2006). Como elemento «distorsionador» del mercado trabajo agrario de Andalucía y Extremadura (Cansino, 2003; García, 2004, García y Troncoso, 2011) marcado por la importantísimas «diferencias territoriales» que supone el paro agrario en nuestro país donde las tasas ofrecidas por le EPA en 1984 señalaban unos valores para Andalucía y Extremadura que casi triplicaban o duplicaban la media nacional respectivamente $-33 \%$ y $25 \%$ frente al $12 \%-$, aspecto éste que será determinante para la implantación del SDA (Cansino y Gómez, 1997; Gómez y Prieto, 2003; Fernández-Cavada; Martín-Fernández y Ortuño-Pérez, 2007). Incluso el SDA permite el mantenimiento de una población, de forma eventual y temporera y bajo el prisma de la movilidad y el nomadismo, para el abastecimiento de fuerza de trabajo de otras actividades económicas no agrarias, denominadas por el autor como «complejo agricultura-construcción-hostelería» (Sánchez, 1980). Una cuestión diferente, que aquí no podemos abordar, es el papel que tanto el sector agrario como estas prestaciones están jugado durante la actual crisis amortiguando las tasas de paro y actuando como sector refugio y factor de resiliencia territorial en Andalucía (Sánchez, Gallardo y Ceña, 2014).

En otros casos los trabajos se han centrado en el papel que el SDA ha venido desempeñando dentro de los sectores más intensivos en mano de obra, básicamente ligados al sector del litoral andaluz con referencia básica en las provincias de Almería y Huelva, y especialmente en su relación con la inmigración que no sólo encuentra trabajo -legal e ilegal- en la actividad agraria (Barco, 2002; Avellá, 2002; Mendoza, 2002; García, 2004; Gualda, 2005; Díaz, 2009; Torres, Allepuz y Gordo, 2014; Márquez, 2014) desplazando de tal actividad a los trabajadores autóctonos que encuentran trabajo mejor remunerado en el sector de la construcción y los servicios, proceso que es entendido como de «movilidad social ascendente» (Pumares, 2006). Dicho proceso tras la actual crisis parece haberse revertido pero no de forma tan automática como podría parecer en la medida en que siguen existiendo reticencias por parte del trabajador autóctono a volver a la actividad agraria en la medida en que persiste 
«una valoración marcadamente desfavorable de las condiciones laborales del sector» al que sólo se recurre «después de haber agotado cualquier otro recurso, desde el subsidio por desempleo hasta la ayuda económica y asistencial puesta en marcha por la red familiar» (Escobar, Galera y Bermúdez, 2012: 214-215). En esta misma línea han de señalarse los trabajos que ponen el énfasis, total o parcialmente, en el papel de la mujer dentro del sector agrario y, claramente y en relación con él, su participación como perceptora de las prestaciones por desempleo eventual agrario (García y Cruz, 1995; Langreo, 2004; Cruces y Palenzuela, 2006). Máxime cuando con el devenir de los años, los cambios normativos, el envejecimiento del colectivo y su feminización las convierta de «colectivo invisible» al mayor perceptor. El no haber salido del sistema bien por no poder al estar inmersas en la rueda del temporerismo (Nuevo, 2000), bien por no querer en busca de unos ingresos mayores, agrarios o no agrarios, lo que acarrearía una movilidad territorial a la que no siempre puede o quiere acceder y que la limita laboralmente (Camarero, 2009), las termina convirtiendo en el colectivo más beneficiado. Dos aspectos más nos señalan dos trabajos recientes a este respecto. A pesar de que la superación de las desigualdades por género se estaba produciendo de forma lenta en el mundo rural español, especialmente en lo referido a las condiciones de trabajo y expectativas personales, siendo las condiciones para las mujeres rurales andaluzas peores en estos aspectos, el colectivo entrevistado responde «mayoritariamente estar satisfechas con sus pueblos». Los avances en el desarrollo rural, señala el estudio -y el de las prestaciones como el SDA o RA, decimos nosotros-, han creado un entorno positivo que valoran de la misma forma (MARM, 2011a, 2011b; Gálvez y Matus, 2012: 214-215).

Otro aspecto que se ha relacionado con el SDA es el denominado «voto cautivo». Se ha sostenido que su implantación y mantenimiento a lo largo del tiempo se ha debido al claro y progresivo beneficio político del partido que los implantó y lo mantuvo. No en vano, con la subida al poder del Partido Popular se puso en marcha una reforma normativa que pretendía su eliminación, el llamado «decretazo». La presión social liderada por los sindicatos obligó a dar marcha atrás en las intenciones del Gobierno de Aznar, no sin modificaciones normativas importantes que más tarde se comentarán. Los trabajos de González (1997), Corzo (2002) o Robles (2003) ponen de manifiesto que no existe una relación causa-efecto entre percepción del SDA y voto a los partidos de izquierda, lo que no es óbice para señalar que, históricamente, dicho voto encuentra en el mundo rural uno de sus principales pilares (Jiménez et al., 2012).

Mucho más complicado es encontrar trabajos en los que se analicen las repercusiones territoriales para el conjunto andaluz o extremeño. Cuando existen se centran en la escala provincial, por ejemplo, Román (2004), Observatorio de empleo agrario andaluz (2004, 2006, 2008) o Cejudo E., Maroto, J.C. y Navarro, F. (2013: 725) señalan una distribución territorial del SDA en las provincias andaluzas entre 1984 y 2010 cada vez más concentrada: «Sevilla representa el $30 \%$ de los subsidiados andaluces seguida de Córdoba con valores en torno al $17 \%$, Granada y Jaén en torno al 13\%. En el extremo opuesto encontramos las provincias de Almería con valores que nunca han alcanzado el 5\%». Pocos ejemplos se encuentran de trabajos que aborden esta cuestión a nivel comarcal y menos aún municipal, salvo los estudios de caso cuando los trabajos profundizan en aspectos, básicamente, cualitativos. Únicamente existe un análisis territorial a escala comarcal del SDA en relación con el mercado de trabajo agrario, aunque breve y accesorio, realizado por Langreo (2002) en el que ya se apunta la relación de 
éste con el cultivo del olivar, su eventualidad, al igual que la desvinculación que origina con el mercado de trabajo. Por otra parte, existen una serie de trabajos que tratan de esclarecer el impacto del subsidio en la población extremeña, así Sánchez y Vicéns (2010: 142), señalan que el SDA «no ha logrado parar el proceso de pérdida de habitantes de los municipios en los que es de aplicación». Por su parte, Jofre-Monseny (2012: 16) opina que «los beneficios del desempleo pueden afectar significativamente a la localización de las personas y las actividades económicas en un país, reduciendo los incentivos a desplazarse desde las zonas de baja productividad a las de alta». Por tanto, a pesar de no lograr frenar los procesos de pérdida de habitantes, sí reducen los desplazamientos de éstos hacia otros espacios más desarrollados.

En definitiva, detrás de la pantalla que identifica subsidio con fraude, paro, voto cautivo, etc., se ha olvidado y minusvalorado la importancia que el SDA y la RA han jugado en la dinámica y articulación territorial de Andalucía y Extremadura. Su importancia geográfica así como sus implicaciones geopoblacionales requieren de un trabajo que las aborde a una escala más adecuada.

Nuestro artículo tiene como principal objetivo analizar las causas de la distribución territorial del SDA y la RA en Andalucía, y detectar sus implicaciones y afecciones geopoblacionales. Con ello, se pretende esclarecer la importancia de este tipo de política en la ordenación territorial del mundo rural de esta región. Estamos convencidos de que el SDA y la RA ha favorecido el mantenimiento de la población de estos territorios, reduciendo la sangría migratoria aunque sin taponarla en su totalidad, propiciando el sostenimiento de una estructura de los asentamientos mucho más equilibrada y uniforme, territorialmente hablando, que el de otras Comunidades Autónomas en las que el despoblamiento se ha cebado de forma irreversible, o casi, -pensamos, por ejemplo, en Castilla y León- Ello es así en la medida en que la distribución del colectivo TEAS ni ha sido ni es homogénea por el territorio andaluz, como tampoco lo es su importancia sociodemográfica en cada uno de los diferentes espacios que lo conforman, ni el perfil del colectivo que se ve beneficiado por estas prestaciones de carácter asistencial, entre otras cuestiones.

Es por ello que este objetivo principal se concretará en:

1. Analizar la evolución de este colectivo en base a umbrales de población municipal.

2. Analizar la distribución, evolución e importancia sociodemográfica de este colectivo a nivel municipal y comarcal.

3. Analizar la evolución y distribución del proceso de envejecimiento y feminización de los TEAS.

4. Y, por último, valorar las consecuencias de dicha distribución territorial y geopoblacional.

Las fuentes de información utilizadas para el trabajo con datos municipales, han sido, por una parte, los colectivos acogidos al SDA, proporcionados por el Servicio Público de Empleo Estatal (SPEE) y el Servicio Andaluz de Empleo (SAE) a través del Instituto de Estadística y Cartografía de Andalucía (IECA), y por otra parte, los nuevos perceptores de la RA procedentes del Servicio Andaluz de Empleo. Del mismo modo, los datos de Afiliación a la Seguridad Social según regímenes por municipios se han obtenido del Ministerio de Empleo y Seguridad Social. Los datos a esta escala de análisis sólo se han 
podido obtener a partir del año 2000, no habiendo posibilidad de acceder a información estadística oficial anterior a esta fecha para el conjunto de los municipios de Andalucía.

Para los análisis provinciales, en unos casos, y para el conjunto del colectivo objeto de estudio se han utilizado tanto los Anuarios como los Boletines mensuales de Estadísticas Laborales publicados por el Ministerio de Empleo y Seguridad Social. Del mismo modo, se ha recurrido a la solicitud, para algunos aspectos concretos, de explotaciones a medida por parte de los Servicios de Estadística de la Seguridad Social.

El intervalo temporal estudiado ha sido, cuando nos refiramos a datos municipales, de once años, desde el año 2000 a 2011. La elección del primer año, 2000, es debido a que la fuente estadística, el IECA, solo proporciona información sobre subsidiados agrarios a nivel municipal a partir de éste momento, tal y como ya se ha señalado anteriormente. Y el último, 2011, porque es el año en el cual finaliza el denominado Régimen Especial Agrario de la Seguridad Social (REASS), incluyéndose a partir de 2012 como Sistema Especial dentro del Régimen General de la Seguridad Social. Cuando los datos hacen referencia a escalas provinciales o superiores los datos hacen referencia al periodo 1984-2011.

El análisis ha sido cuantitativo y espacial, tratando de reflexionar sobre la distribución geográfica del colectivo de TEAS, a través de los tres niveles máximos de desagregación espacial: por intervalos de población provincial, comarcal y municipal, siendo el segundo «el ámbito territorial lógico para el estudio del mercado de trabajo e incluso del factor trabajo ya que en él se produce el intercambio de trabajadores sin necesidad de migraciones» (Langreo, 2002: 203). Añadir también, que se ha podido tener en cuenta el sexo de los beneficiarios, pero no la edad de éstos, ya que las fuentes anteriormente señaladas no proporcionan tal información a escala municipal.

Por otro lado, el colectivo objeto de estudio es el de los perceptores de prestaciones por desempleo a través del Subsidio Agrario o de la Rente Agraria. Se trata de unas prestaciones «no contributivas» o «asistenciales» destinadas a los trabajadores eventuales agrarios por cuentan ajena que se encuentren en situación de desempleo y que cumplan los requisitos, criterios y perfiles legalmente establecidos desde su aparición en $1984^{1}$. La desaparición del Régimen Especial Agrario de la Seguridad Social a partir de 2012, en aplicación de la Ley 28/2011, de 22 de septiembre en la que éste se integra en el Régimen General no ha supuesto la extinción de la prestación del Subsidio ni de la Renta Agraria. La desaparición de este se fraguó tras la reforma del sistema de protección por desempleo que se llevó a cabo en el año 2002 por el Gobierno del Partido Popular al imponer que a partir de ese año para obtener una prestación es necesario «haber sido beneficiario del subsidio en alguno de los tres años naturales inmediatamente anteriores a la fecha de solicitud», imposibilitando el acceso de nuevos perceptores. Las críticas a la reforma y la movilización social consecuente condujo a la implantación de la actual Renta Agraria $^{2}$.

Con su promulgación se consolida la estructura del sistema de protección por desempleo de los trabajadores eventuales agrarios de Andalucía y Extremadura. Por una parte, el SDA para los trabajadores que habían sido perceptores del mismo durante los tres años

1 Para más información véase Cejudo, Maroto, Navarro, 2013.

2 A través de RD 864/2006 de 14 de julio para la mejora del sistema de protección por desempleo de los trabajadores agrarios. BOE $n^{\circ} 168$ de 15 de julio. Las prestaciones se fijan en el RD 426/2003, de 11 de abril, BOE $\mathrm{n}^{\circ} 88$ de 12 de abril. 
anteriores a la solicitud y para el resto, es decir, para los que no pudieran acceder al Subsidio, la RA. Así las cosas el Subsidio se configura como una prestación de carácter transitorio y, por tanto, a extinguir. Ahora bien, la progresiva sustitución del SDA por la RA no supone que sus elementos estructurales desaparezcan por completo, todo lo contrario, lo que permite concluir que ésta es la continuación en el tiempo de aquél, condenado como está a su extinción (Romero, 2009: 351-375).

\section{RESULTADOS: LA DISTRIBUCIÓN ESPACIAL DE LOS TEAS}

La distribución territorial de los TEAS a escala regional andaluza muestra una serie de tendencias que, a rasgos generales, son las siguientes: la relación -a varios niveles- entre TEAS y mundo rural-agrario; la reducción en su número, que conlleva una mayor concentración territorial; una distribución cada vez más ligada al olivar; y por último, la tendencia a la feminización-envejecimiento del colectivo. Ahora bien, estas pautas presentan sus matizaciones, sobre todo en lo que respecta a la feminización y el envejecimiento, ligadas principalmente, y como se ha mencionado anteriormente, a la aparición de un nuevo tipo de prestación a comienzos de la década pasada, la RA.

\section{II.1. La reducción en su número, su concentración territorial en municipios de tamaño interme- dio (2.000-5.000 hab.)}

La progresiva reducción en el tiempo del número de TEAS ha ido paralelo a una mayor concentración territorial. Es decir, este tipo de prestación cada vez presenta una menor significación, teniendo en su explicación múltiples causas que tienen que ver, por una parte, con la propia dinámica del mercado laboral, ya ligado a actividades agrarias -la reducción de mano de obra necesaria en el sector, especialmente en una actividad demandante como el olivar en base a una importante tecnificación, especialmente de la recogida-, ya rurales a través de la diversificación productiva, en muchos casos, de estos espacios, ya ligado a actividades como la construcción y los servicios relacionados con el turismo -si se quiere más «urbanas»- que se convierten en una alternativa más atractiva para el empleo; los propios cambios normativos que han ido cerrando el flujo a la incorporación de nuevos perceptores, proceso que se inició ya en los primeros 90 y al que se volvió a dar una nueva vuelta de tuerca en 2002. Si le sumamos a todo ello, además, la creciente salida del sistema, a través de la jubilación, de unos efectivos cada vez más envejecidos, tendremos las grandes líneas que marcarían su devenir histórico. En efecto, los casi 200.000 TEAS de 1984 se llegaron a convertir en casi 300.000 en los años 1989-90 para caer en picado hasta los 201.000 en 1992. Una evolución oscilante con valores en torno a los 220.000 beneficiarios y que alcanzará su cénit en 2001, año previo a la puesta en marcha de la reforma del Partido Popular -suman los 233.495-, para desde entonces poseer una tendencia descendente sólo rota en los dos últimos años de la serie que se analiza -ligada a la vuelta a la actividad agraria como sector refugio de la actual crisis-. Andalucía muestra una evolución idéntica a la señalada a nivel general en la medida en que a ella pertenecen entre el 85 y $87 \%$ del total de TEAS. Ello se traduce en que si para el año 2.000 este colectivo suponía 195.470 subsidiados, once años después (2011) estaban reducidos a 175.028 , un $10,5 \%$ menos, y distribuidos por un menor número de municipios. 
Tabla 1

IMPORTANCIA DE LOS TEAS SEGÚN TAMAÑO POBLACIONAL DE LOS MUNICIPIOS ANDALUCES, AÑOS 2000 Y 2011

\begin{tabular}{|c|c|c|c|c|c|c|c|c|c|}
\hline \multirow{3}{*}{$\begin{array}{l}\text { Intervalos } \\
\text { de } \\
\text { Población }\end{array}$} & \multicolumn{7}{|c|}{ Trabajadores Eventuales Agrarios Subsidiados } & \multicolumn{2}{|c|}{$\begin{array}{c}\text { Afiliados a la Seg. } \\
\text { Social }\end{array}$} \\
\hline & \multicolumn{2}{|c|}{ Total } & \multicolumn{2}{|c|}{ Mujer } & \multirow{2}{*}{$\begin{array}{c}\text { Tot/Pob } \\
15-64\end{array}$} & \multirow{2}{*}{$\begin{array}{c}\text { Muj/Muj } \\
15-64\end{array}$} & \multirow{2}{*}{$\begin{array}{l}\text { Índice } \\
\text { feminidad }\end{array}$} & \multirow{2}{*}{$\begin{array}{c}\text { Agraria/ } \\
\text { Total }\end{array}$} & \multirow{2}{*}{$\begin{array}{c}\text { TEAS/ } \\
\text { Afil_- } \\
\text { Agr }\end{array}$} \\
\hline & Abs. & $\%$ & Abs. & $\%$ & & & & & \\
\hline \multicolumn{10}{|c|}{ Andalucía 2000} \\
\hline $0-499$ & 1.594 & 0,82 & 763 & 0,66 & 9.0 & 9.2 & 91.8 & 60.27 & 38,45 \\
\hline $500-999$ & 5.132 & 2,63 & 2.779 & 2,41 & 11.3 & 12.8 & 118.1 & 56.51 & 41,96 \\
\hline $1.000-1.999$ & 15.583 & 7,97 & 8.888 & 7,70 & 12.1 & 14.3 & 132.8 & 60.46 & 45,57 \\
\hline $2.000-4.999$ & 48.002 & 24,56 & 27.976 & 24,22 & 11.8 & 14.1 & 139.7 & 54.73 & 41,94 \\
\hline 5.000-9.999 & 46.684 & 23,88 & 27.322 & 23,66 & 9.1 & 10.9 & 141.1 & 44.78 & 44,03 \\
\hline $10.000-19.999$ & 40.347 & 20,64 & 24.675 & 21,37 & 5.9 & 7.3 & 157.4 & 34.70 & 37,58 \\
\hline $20.000 y+$ & 38.128 & 19,51 & 23.085 & 19,99 & 1.2 & 1.4 & 153.5 & 8.95 & 24,88 \\
\hline \multicolumn{10}{|c|}{ Andalucía 2011} \\
\hline $0-499$ & 1.239 & 0,71 & 713 & 0,62 & $\begin{array}{r}6.2 \\
\end{array}$ & 7.7 & 135.6 & 47.2 & 40.4 \\
\hline $500-999$ & 4.041 & 2,31 & 2.359 & 2,06 & 8.5 & 10.7 & 140.2 & 49.9 & 41.1 \\
\hline $1.000-1.999$ & 10.572 & 6,04 & 6.386 & 5,58 & 9.3 & 12.0 & 152.6 & 54.8 & 39.6 \\
\hline $2.000-4.999$ & 41.904 & 23,94 & 26.209 & 22,92 & 9.9 & 12.9 & 167.0 & 52.5 & 39.9 \\
\hline $5.000-9.999$ & 39.556 & 22,60 & 25.672 & 22,45 & 7.5 & 10.1 & 184.9 & 44.3 & 36.5 \\
\hline $10.000-19.999$ & 33.291 & 19,02 & 22.261 & 19,46 & 4.7 & 6.5 & 201.8 & 32.8 & 35.7 \\
\hline $20.000 \mathrm{y}+$ & 44.425 & 25,38 & 30.767 & 26,90 & 1.1 & 1.6 & 225.3 & 8.7 & 26.2 \\
\hline
\end{tabular}

Fuente: Padrón municipal de habitantes, www.seg-social.es/Internet_1/Estadistica. Elaboración propia.

Este fenómeno, de reducción-concentración se aprecia, en primer lugar, en el estudio por intervalos de población a escala municipal - ver tabla 1-. Uno de los primeros hechos que se destacan es que entre las dos fechas comparadas se produce una concentración de los TEAS en los municipios «urbanos»-si se entienden por tales los de 10.000 y más habitantes- al pasar del 40,1 al 44,4\%, exclusivamente por el crecimiento de la categoría de 20.000 y más habitantes -se pasa del 19,5 al 25,4\% del total-, la única que crece frente al descenso relativo de todas las demás. Ese mismo proceso se comprueba con mayores niveles -casi un 1\%para el caso del colectivo femenino. Este hecho entendemos que, siendo importante, en la medida en que a principios de este milenio eran las categorías de 2.000-4.999 y 5.000-9.999 los que más TEAS acogían, ahora es la de 20.000 y más la que ocupa esta posición privilegiada, merece ser matizada y contextualizada a fin de no llegar a conclusiones erróneas que identifique prestación por desempleo agrario con la ciudad.

En efecto, no convendría perder de vista que en Andalucía uno de los elementos identificativos de su estructura territorial es la importante presencia de municipios que por su volumen demográfico podría ser calificadas como ciudades -más de 10.000 habitantes- pero en las que la actividad agraria sigue jugando un papel destacado en su estructura productiva y laboral, las denominadas como «agrociudades». Es más, hay que tener presente que esta misma categoría es la única que incrementa de forma significativa su 
población en un 24\% -los demás intervalos presentan una clara estabilidad en sus efectivos entres las dos fechas salvo el considerable descenso, un 15\%, del intervalo 1.000-1.999.

Este hecho se traduce en que el número de municipios que se incluiría en el siguiente intervalo, 20.000 y 49.999 habitantes, pasa a agrupar en 2011 a 52 municipios, frente a los 38 de 2000, concentrando en 2011 el 69,6\% del total de TEAS del intervalo 20.000 y más, cuando en el año 2000 eran el 45,6\%. Esto mismo se reproduce aun con mayor intensidad para el caso de las mujeres, un 3\% más. En otras palabras, el incremento del número de agrociudades que sobrepasan durante el intervalo estudiado los 20.000 habitantes está en el origen de este comportamiento ${ }^{3}$. Además de tener en cuenta este contexto andaluz hay que matizar la afirmación anterior en la medida en que la mayor parte de los perceptores siguen viviendo en zonas rurales, especialmente en los municipios comprendidos entre los $1.000 \mathrm{y}$ 4.999 habitantes, en 46,5\% en 2011 frente al 48,4\% del año 2000.

Esta realidad quedaría incompleta si no se relaciona a este colectivo con la población de sus diferentes municipios. Así, son los términos con tamaño intermedio (intervalos de 2.0005.000 hab., e incluso de 1.000-2.000), los que poseen mayor importancia de nuestro colectivo. Si en el año 2000, la mayor abundancia la encontrábamos en el intervalo de 1.000-2.000 hab. (12,1\% de TEAS respecto a la población comprendida entre 15-64 años), para el año 2011, será el intervalo siguiente, de 2.000-5.000 hab., el que posee mayor porcentaje (9,9\%). La menor incidencia de los procesos de envejecimiento en este último intervalo, de 19,3\% frente a 26,9\% en el intervalo de menor población (0-500 hab.), particularmente en el sector agrario, y la mayor presencia de féminas, explicaría tal fenómeno, junto con la abrumadora supremacía en éstos del cultivo del olivar, el cual, conlleva largas temporadas de carencia de labores. De ello también se deriva que el porcentaje de afiliados agrarios sobre el total de afiliados sea superior en los intervalos de 1.000-2.000 hab., (54,8\% para 2011), e incluso, de 2.000-5.000 hab. $(52,5 \%)$, respecto a intervalos inferiores, situados estos últimos por debajo del $50 \%$.

Por otra parte, y complementando lo anterior, -ver fig. 1 y 2- de los tres ejes paralelos en los que se distribuye el empleo agrario en nuestra región: campiñas del Guadalquivir, Subbética olivarera y agricultura intensiva litoral, el colectivo de TEAS tiende a concentrarse sobre todo en el segundo, la Subbética olivarera. Así, para el año 2011, si observamos tanto la figura 2 como la tabla 2, apreciamos que coincide casi prácticamente con este paralelo, abarcando desde la Sierra Sur (Sevilla), en el Oeste, hasta la Sierra de Segura (Jaén), al Este, alcanzando incluso hasta la vecina comarca de El Condado (Jaén), discurriendo por comarcas de la Subbética con clara presencia del monocultivo del olivar (por ejemplo, Sierra Sur y Sierra Mágina, para Jaén; y Montes Occidentales y Montes Orientales, para Granada). Otro hecho que corrobora la anterior afirmación, es que si correlacionamos \% TEAS entre 15-64 años con \% de superficie de olivar, para los municipios andaluces, obtenemos un resultado de 0,35 , es decir, una media correspondencia entre ambos.

Por tanto, el monocultivo del olivar en la media montaña subbética es uno de los principales sistemas socioeconómicos que explicarían la localización del colectivo de TEAS, al poseer largos periodos del año sin apenas labores, lo que obliga a los trabajadores a percibir

3 Sin ánimos de ser exhaustivos es el caso de Guadix, Loja, Baena, Palma del Río, Lora del Río o Conil de la Frontera. Municipios en los que la ratio entre los afiliados al REASS suponen más del $40 \%$ del total de afiliados a la Seguridad Social, lo que demuestra bien a las claras la importancia de su sector agrario. 
Figura 1

TEAS RESPECTO DE LA POBLACIÓN DE 15 A 64 AÑOS SEGÚN COMARCAS AGRARIAS, AÑO 2000, (\%)

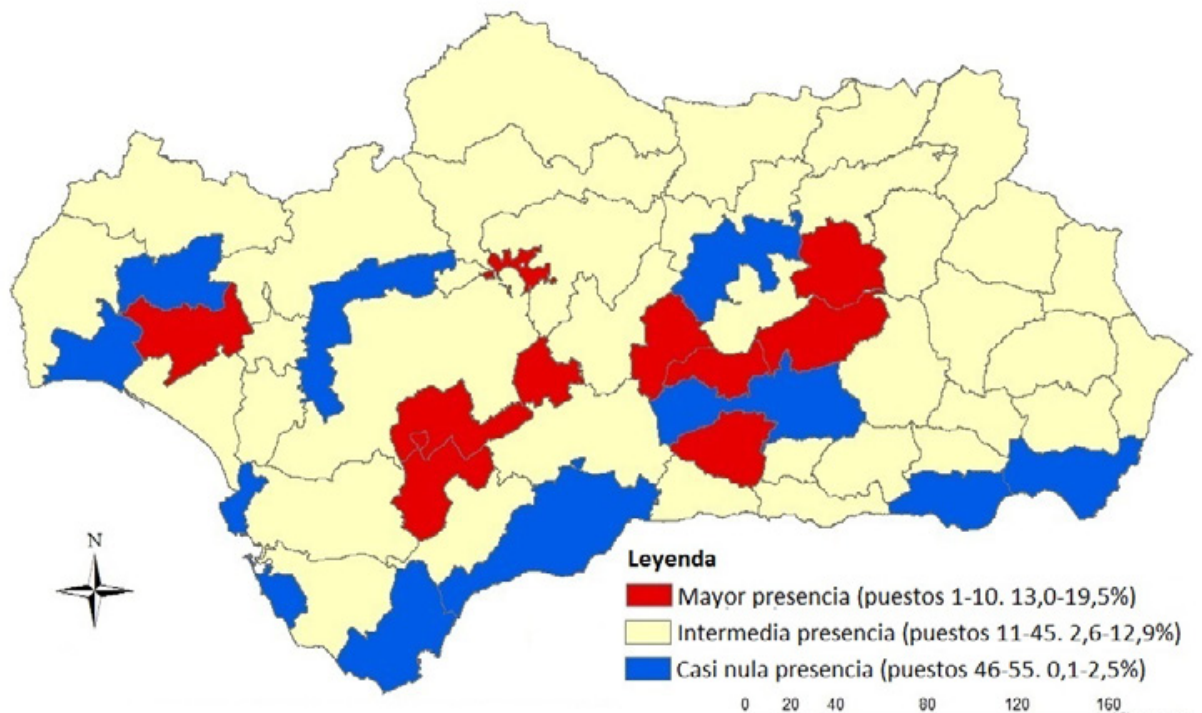

Fuente: Instituto de Estadística y Cartografía de Andalucía. Elaboración propia.

Figura 2

TEAS RESPECTO DE LA POBLACIÓN DE 15 A 64 AÑOS SEGÚN COMARCAS AGRARIAS, AÑO 2011, (\%)

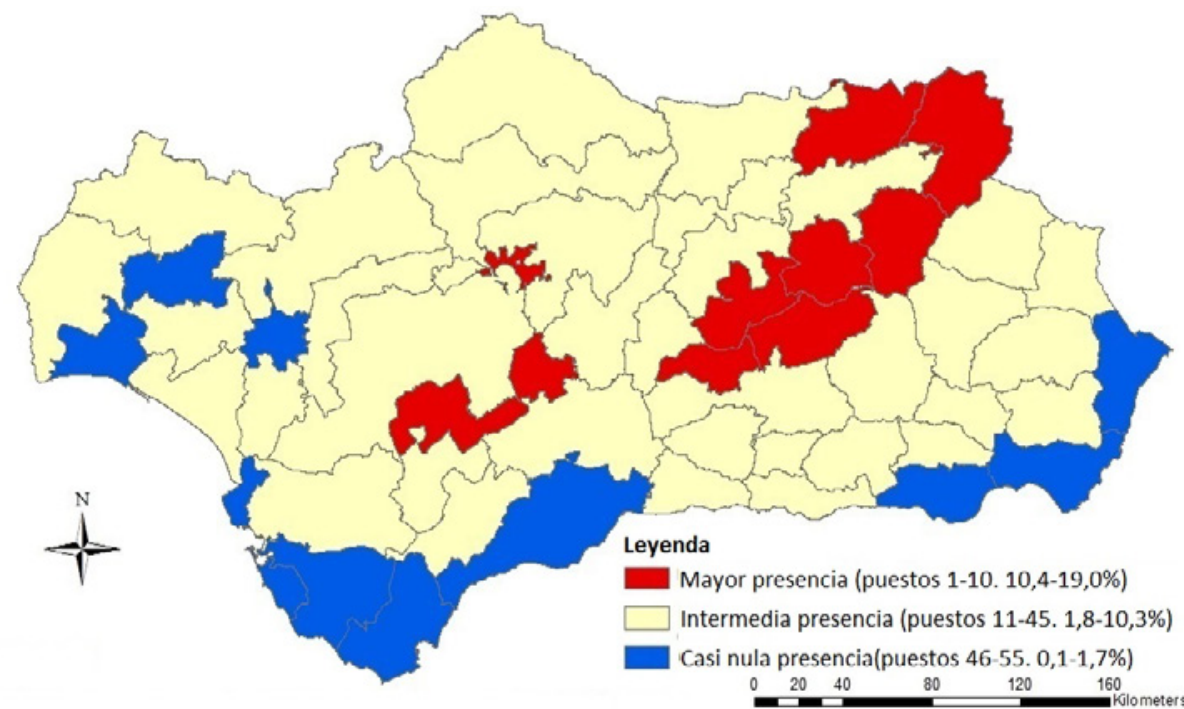

Fuente: Instituto de Estadística y Cartografía de Andalucía. Elaboración propia. 


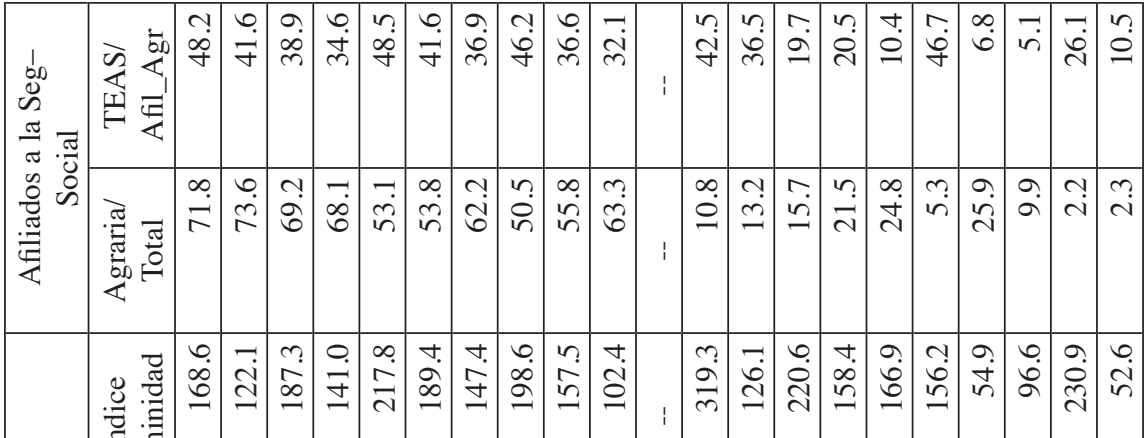

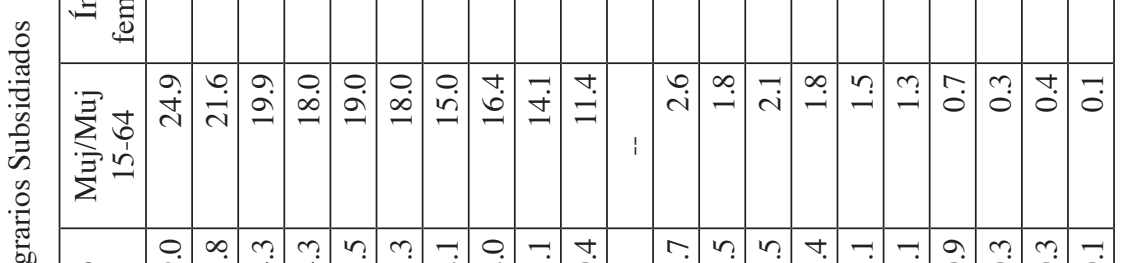

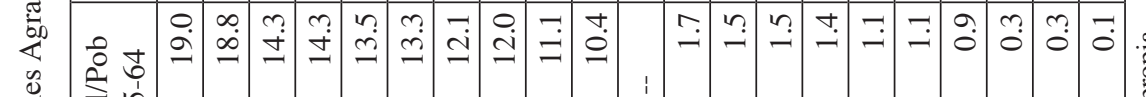

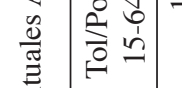

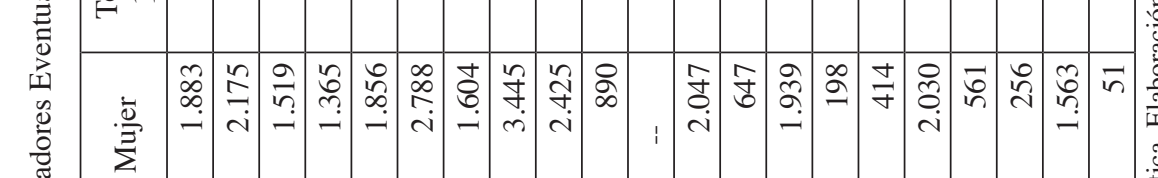
$\sim$

능

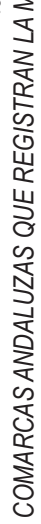

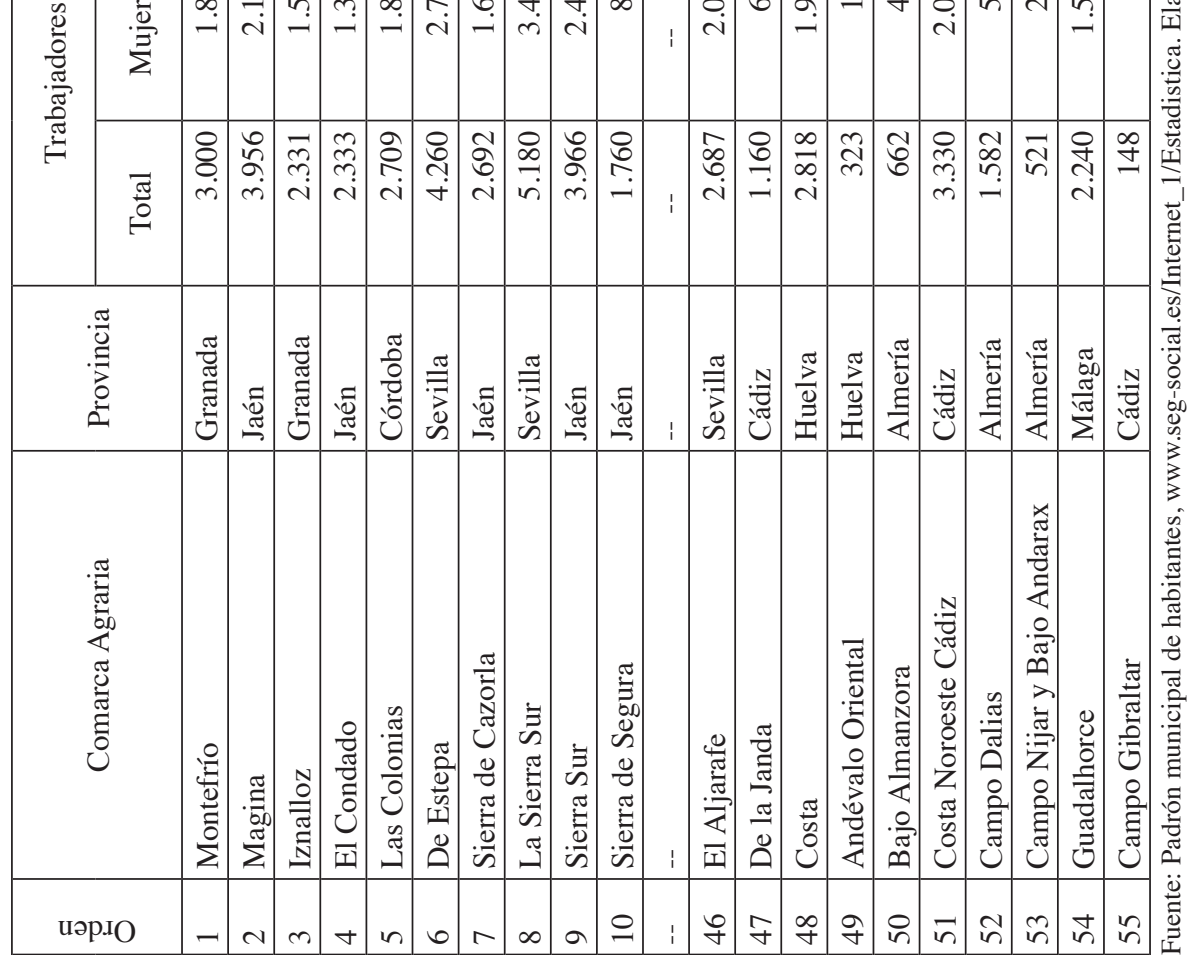


tal ayuda. Este hecho también da sentido al apelativo que se le otorga al olivar de «cultivo social», además de ser el que ocupa al $32 \%$ de la mano de obra agraria andaluza. Es la principal actividad de más de 300 pueblos de esta región en los que viven más de 250.000 familias (Junta de Andalucía, 2009, 2011), de ahí su importancia territorial y poblacional. Por tanto, los requerimientos de trabajo concentrado, eventual, y sin apenas necesidad de cualificación en el olivar ayudarían a entender gran parte de su distribución espacial.

Por último, en el paralelo de la agricultura intensiva litoral, apenas aparece representado nuestro colectivo. De hecho, entre las 10 con menor presencia de TEAS aparecen dos comarcas con claro predominio de la agricultura intensiva de invernadero (Campo de Dalías y Campo de Níjar y Bajo Andarax). En el caso del sector fresero de Huelva (representado en la comarca de la Costa), se recurre mayoritariamente a mano de obra femenina a través de fórmulas como el contrato en origen en países de la Europa del Este. Y en el caso de la hortofruticultura almeriense, para suplir las importantes necesidades de mano de obra se recurre a mano de obra extranjera -legal e ilegal-. Ello explicaría la apenas presencia de TEAS en las comarcas litorales, unido a la localización en ellas de grandes áreas urbanas y metropolitanas (Cádiz y Málaga), y a la existencia del sector turístico, algunas veces complementario al sector hortofrutícola (casos de Almería y Huelva), y otras veces sector preponderante en la economía litoral (caso de Málaga).

Este fenómeno de reducción de la importancia porcentual del colectivo de TEAS respecto al grupo de población comprendido entre 15-64 años y su mayor representatividad en el área de la Subbética olivarera, se aprecia también en la escala municipal -ver tablas 3 y 4-, sobre todo de Granada y Jaén, perdiendo protagonismo relativo en los municipios de las campiñas de Sevilla y Córdoba, además de en la mayor parte de los municipios de Almería, Huelva y Cádiz.

A rasgos generales, los mayores porcentajes con respecto a la población de 15-64 años, superiores al 15\%, se encuentran en las áreas coincidentes con la Subbética olivarera, y en menor medida, en las Campiñas del Guadalquivir. Por tanto, es en los municipios de esta área donde el SDA y la RA adquieren mayor importancia y presentan más efectos sobre el tejido poblacional, social y económico. De hecho, si se aprecia la tabla 3 , de los diez municipios con mayor importancia del colectivo de TEAS, por encima del 24,7\%, 7 de ellos se encuentran inmersos dentro del área de la Subbética olivarera, 2 de ellos en la Campiña del Guadalquivir, y 1 en Sierra Morena.

Como es lógico, en el extremo opuesto, por debajo del 5\% encontramos a municipios turísticos litorales (por ejemplo, Mojácar, Benalmádena y Torremolinos), urbanos (San Fernando o La Línea de la Concepción), de áreas metropolitanas (Cájar o Víznar en el área metropolitana Granada), e incluso, del rural profundo montano, como Capileira en Granada, o Parauta en Málaga), en los cuales, el abandono de la actividad agraria, junto con el predominio económico del turismo rural han dado lugar a la inexistencia de este colectivo.

Ahora bien, hay que matizar el hecho anterior. Si bien en las Campiñas del Guadalquivir, el otro eje del empleo agrario interior andaluz, la presencia del colectivo de TEAS es menor en cifras relativas, es superior en absolutas. Ello se aprecia en las figuras 3 y 4, donde las tonalidades más fuertes se sitúan en los municipios de las comarcas de campiña de Córdoba y Sevilla, junto con algunos, en menor medida, de la Subbética. Lo anterior se debe a: lógicamente, al mayor tamaño poblacional de estos municipios, donde nuestro grupo de estudio se diluye en mayor medida; la mayor presencia de mujeres entre ellos respecto a otras áreas; 


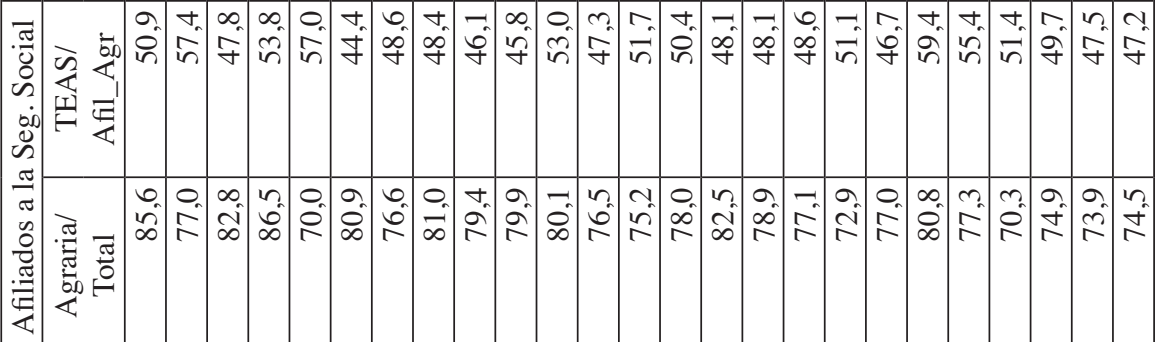

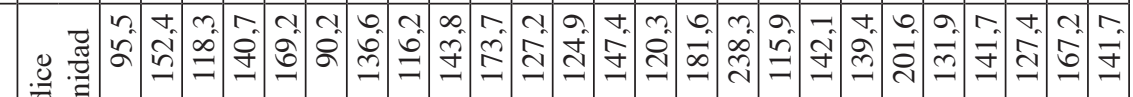
:

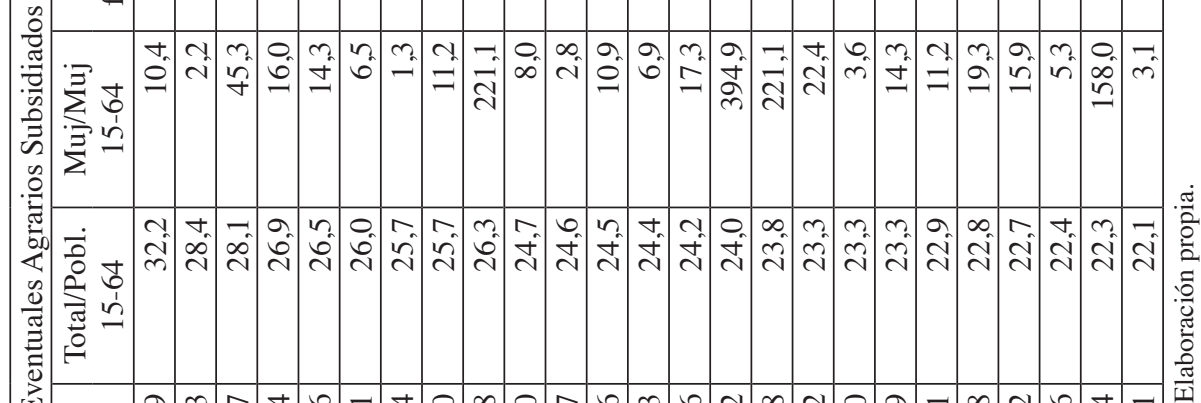

m 앙

$\frac{\pi}{0} \frac{1}{\sqrt{2}}$

文

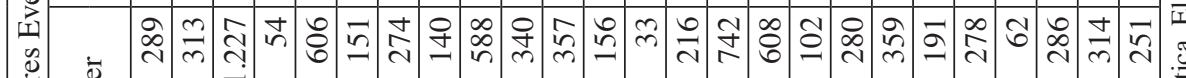

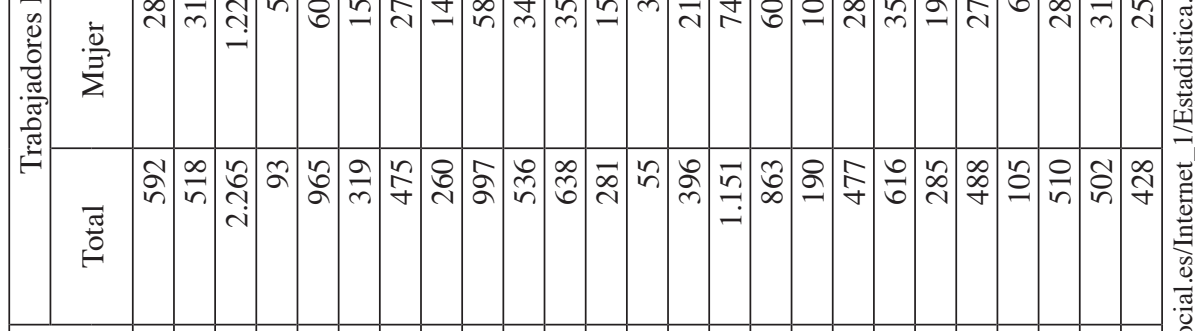

萢

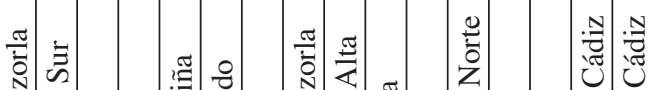

ชูป ปี

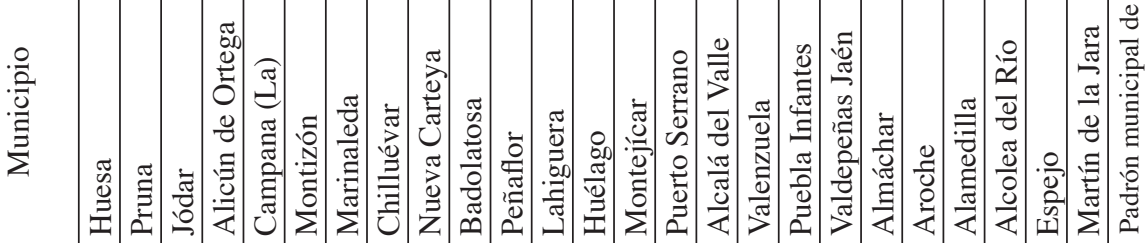

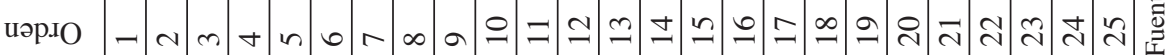




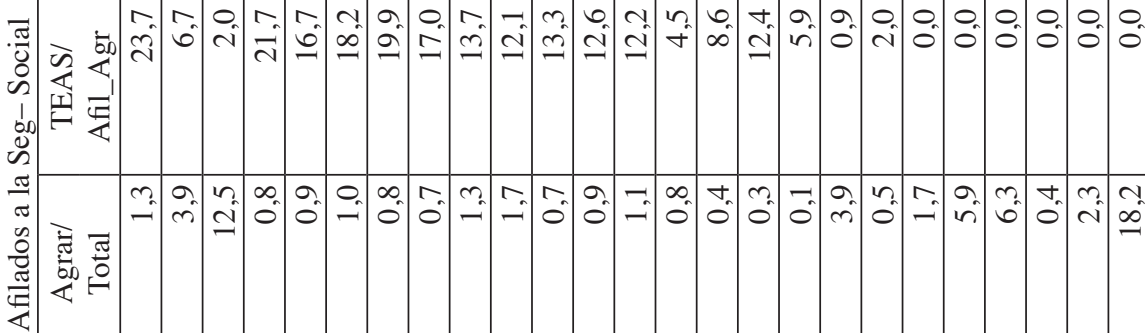

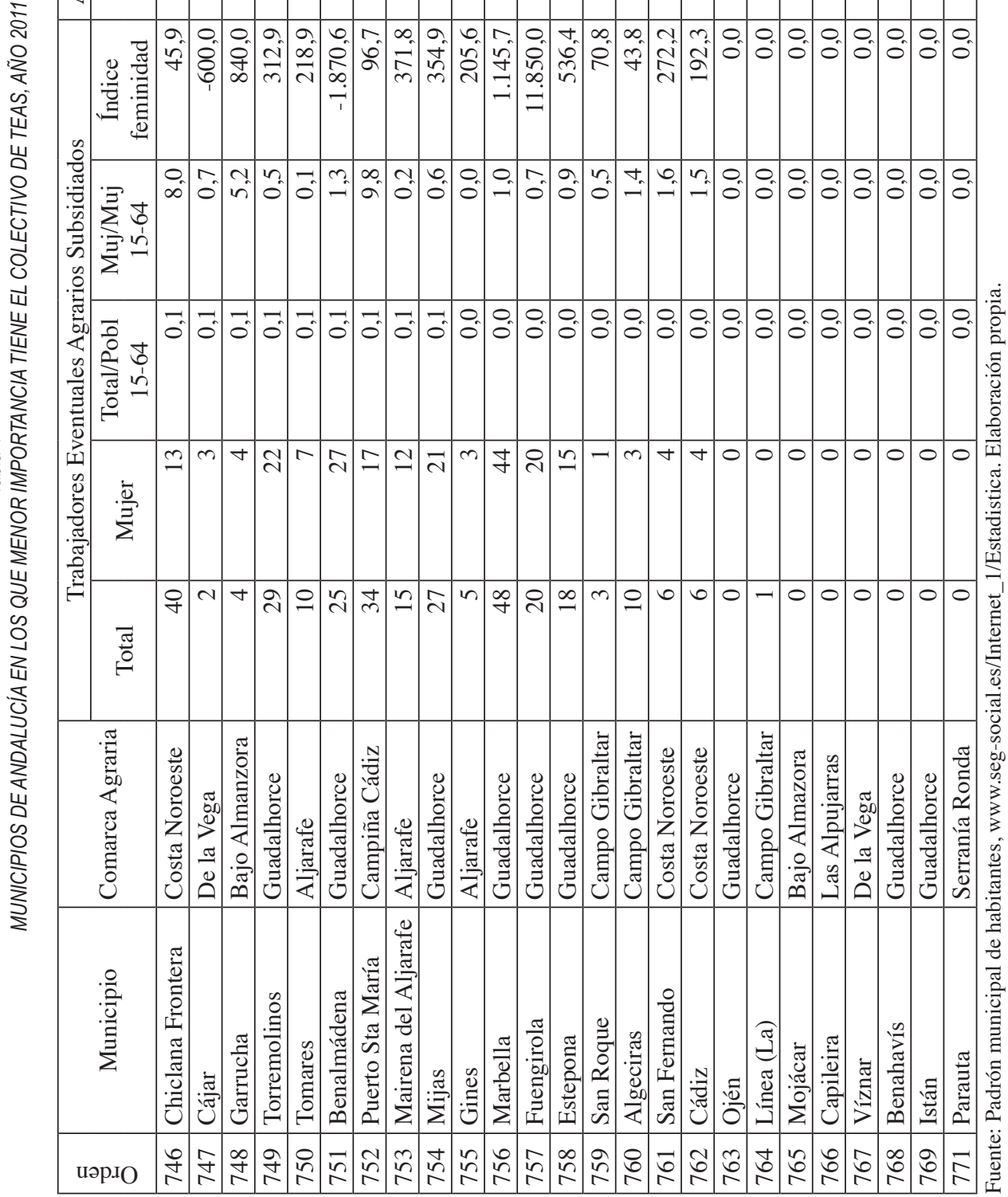


Figura 3

CIFRAS ABSOLUTAS DE TEAS POR MUNICIPIO, AÑO 2000

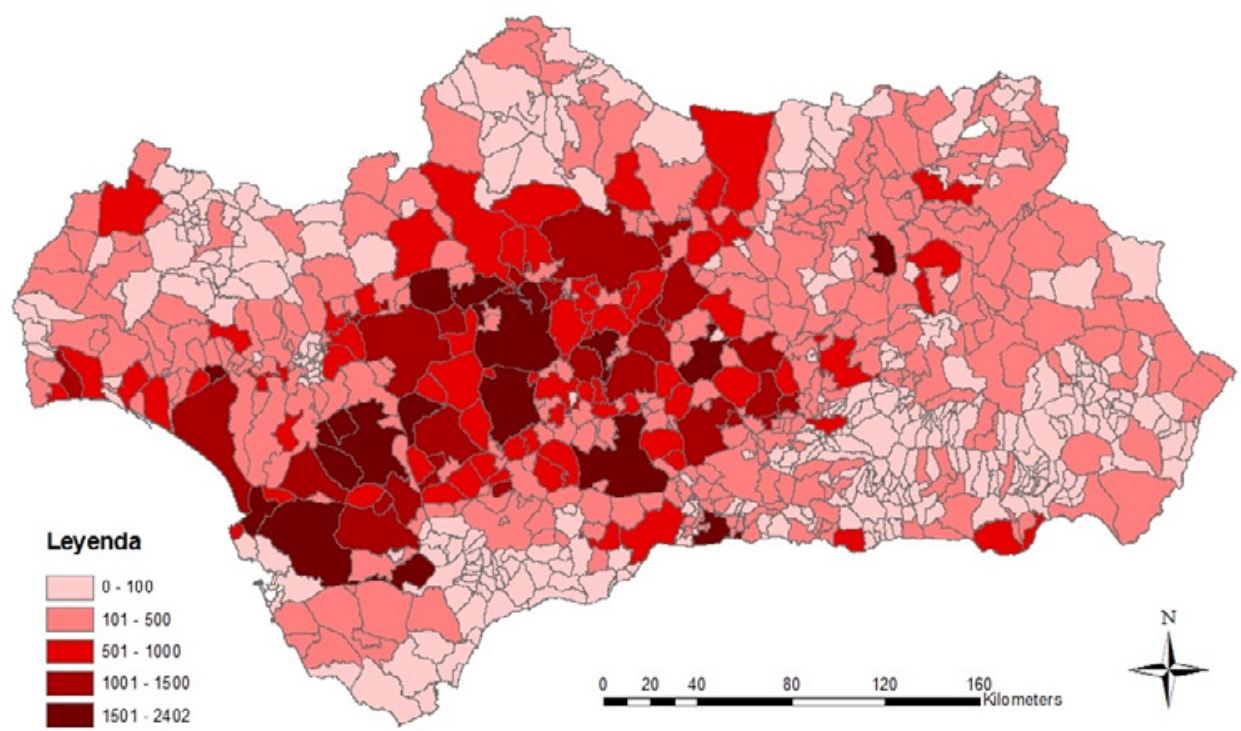

Fuente: Instituto de Estadística y Cartografía de Andalucía. Elaboración propia.

Figura 4

CIFRAS ABSOLUTAS DE TEAS POR MUNICIPIO, AÑO 2011

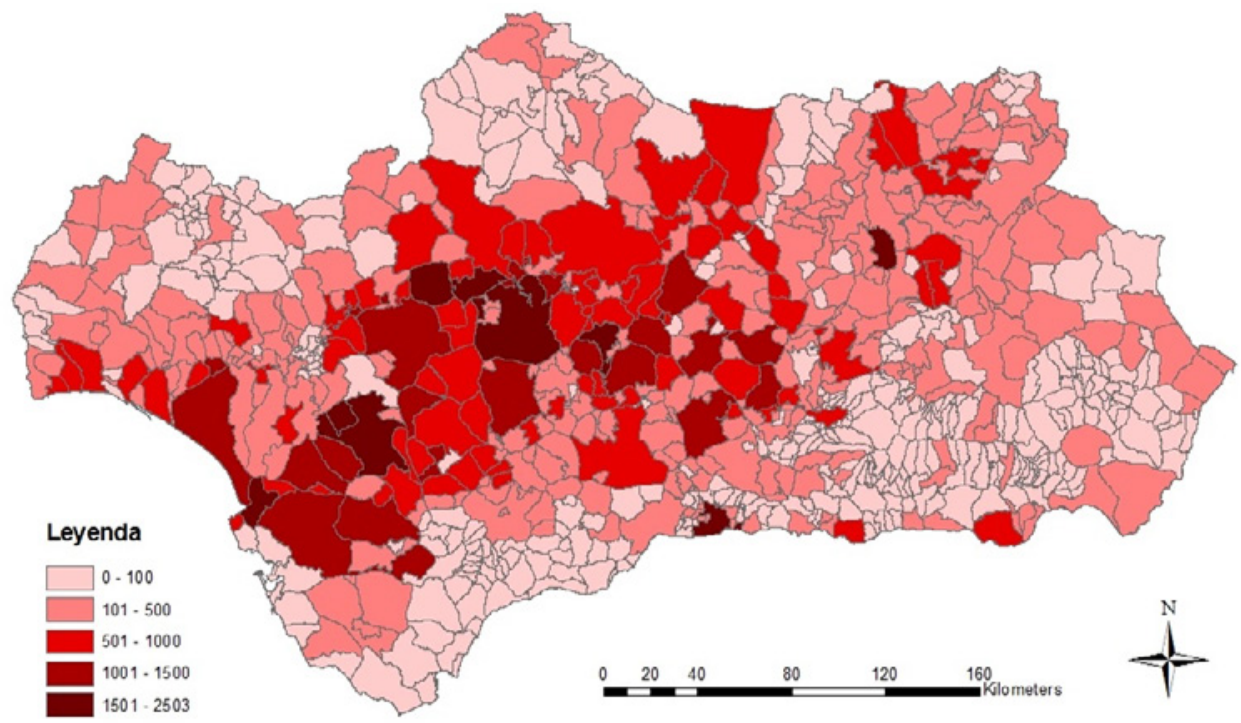

Fuente: Instituto de Estadística y Cartografía de Andalucía. Elaboración propia. 
la preeminencia de otros cultivos (cereales), menos intensivos en mano de obra y con mayor facilidad de mecanización; el mayor tamaño medio de las explotaciones; e incluso, una mayor facilidad de encontrar trabajo en las ciudades medias o agrociudades localizadas en este ámbito. Todo ello contribuye a la reducción porcentual de aquéllos, pero no a su liderazgo en cifras absolutas.

\section{II.2. La necesaria coincidencia en el reparto territorial entre afiliados agrarios y TEAS}

Otro de los principales factores, como no podía ser más lógico, que explica la distribución territorial de este colectivo es la presencia de afiliados agrarios por cuenta ajena. Es evidente, por necesaria, que no puede haber TEAS sin estar, previamente, afiliados al REASS. Así, el coeficiente de correlación, entre el porcentaje de afiliados agrarios sobre el total de afiliados y el porcentaje de TEAS respecto a la población de 15-64 años en el año 2011, es de 0,85 . De hecho, son muchos los autores que señalan una relación causa-efecto entre afiliados agrarios o, más concretamente por cuenta ajena, al punto de señalar que aquellos lo son, en gran medida, para poder acogerse a las prestaciones del SDA o de la RA. Por tanto, la existencia de este subsidio, resalta la permanencia en el sector agrario de una forma «artificial», para obtener esta ayuda. Asumiendo que esa relación existe cuando se trata de situaciones fraudulentas, no se puede afirmar, sin más que ello ocurra de forma causal y generalizada más allá de un de 10-15\% claramente irregular. Ello es así porque cuando se comparan los porcentajes de los afiliados agrarios por cuenta ajena -los únicos que pueden percibir estas prestaciones por desempleo- en relación con el total de afiliados agrarios se comprueba que, siendo claramente superiores en Andalucía y Extremadura respecto de las demás CC.AA., son 10-15 puntos superiores a los de otras con un importante sector agrario altamente demandante de empleo eventual agrario como son Canarias, Murcia o Comunidad Valenciana. No discutimos la relación, sí los automatismos -ver tabla 5-.

Si comparamos la distribución de los afiliados agrarios sobre el total de afiliados y de TEAS sobre afiliados agrarios en 2011 -fig. 5 y 6-, apreciamos que las tonalidades coinciden casi plenamente en ambos mapas, y sobre todo, en los municipios de las provincias de Sevilla, Jaén, Córdoba y Granada.

En los de Huelva y Almería, la presencia de una hortofruticultura intensiva, hace que por sus características laborales, apenas se acuda al SDA, por lo que la coincidencia es casi nula. Por tanto, y abundando un poco más en esta distribución, si se observa la figura 5 se aprecia claramente que las tonalidades más oscuras, es decir, el porcentaje de afiliados agrarios más elevado sobre el total de afiliados a la Seguridad Social, se sitúa sobre los dos ejes paralelos en los que se distribuye el empleo agrario en el interior de nuestra región (Pita y Pedregal 2011): Subbética olivarera y campiñas del Guadalquivir, mientras que el paralelo de la agricultura intensiva litoral queda al margen de este fenómeno.

Lo mismo sucede con los mayores porcentajes de TEAS respecto al total de afiliados agrarios, que se concentran en las dos áreas señaladas anteriormente -ver figura 6-. Además, si observamos de nuevo la figura 7, comarcas con alta ruralidad, por ejemplo, las Altiplanicies, Alpujarras (ambas de Granada), o Los Vélez (Almería), no coinciden con tasas más altas de afiliados agrarios. Incluso, si se considera el tamaño poblacional de los municipios -ver tabla 1-, de 0-500 hab., los afiliados agrarios apenas alcanzan un 47,2\% sobre el total, 


\begin{tabular}{|c|c|c|c|c|c|c|c|c|c|c|c|}
\hline لِ & $\stackrel{m}{n}$ & $\stackrel{0}{0}^{-}$ & $\begin{array}{l}0 \\
\infty \\
-\end{array}$ & $\begin{array}{l}0 \\
\infty \\
-1\end{array}$ & $\begin{array}{l}\ddot{2} \\
\text { ते }\end{array}$ & $\begin{array}{l}\dot{0} \\
\stackrel{\sim}{\sim}\end{array}$ & নे & $\stackrel{n}{\text { ก }}$ & $\begin{array}{l}0 \\
\dot{f}\end{array}$ & $\frac{2}{\sigma}$ & 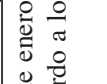 \\
\hline ن : & $\stackrel{3}{\simeq}$ & בิ & $\stackrel{\infty}{=}$ & $\underset{\mathrm{I}}{\mathrm{I}}$ & 热 & $\overline{ \pm}$ & $\stackrel{0}{i n}$ & $\begin{array}{l}\infty \\
i n\end{array}$ & $\begin{array}{l}\text { to } \\
\text { ते }\end{array}$ & ֻે & 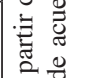 \\
\hline 离 & $\stackrel{\vec{m}}{m}$ & 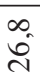 & $\begin{array}{l}\infty \\
\text { d }\end{array}$ & $\vec{a}$ & $\vec{\infty}$ & $\begin{array}{l}0 \\
\text { ¿ }\end{array}$ & in & ๙े & $\begin{array}{l}\infty \\
\text { n. }\end{array}$ & $\begin{array}{c}m \\
\infty \\
\infty\end{array}$ & \\
\hline$\stackrel{\dot{\Xi}}{\dot{\Sigma}}$ & $\stackrel{i}{ \pm}$ & $n$ & jे & $\stackrel{n}{n}$ & $\stackrel{0}{\infty}$ & ஸे & $\begin{array}{l}0 \\
\infty \\
\infty\end{array}$ & के & के & $\begin{array}{l}n \\
2\end{array}$ & \\
\hline$\sum^{\tilde{I}}$ & $\begin{array}{l}n \\
\infty \\
n \\
n\end{array}$ & $\overrightarrow{8}$ & $\frac{\partial}{\bar{n}}$ & $\overrightarrow{8}$ & ले & के & $\begin{array}{l}\infty \\
\text { in }\end{array}$ & $\hat{\sigma}$ & 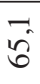 & $\begin{array}{l}+ \\
6 \\
0\end{array}$ & $\begin{array}{l}\text { II } \\
\frac{1}{\sigma}\end{array}$ \\
\hline 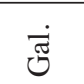 & $\stackrel{\vec{r}}{m}$ & $\stackrel{\sim}{\forall}$ & $\stackrel{\partial}{\dot{\gamma}}$ & $\begin{array}{l}\infty \\
i\end{array}$ & $\theta_{0}$ & $\vec{\sigma}_{0}$ & $\overbrace{0}^{0}$ & $\stackrel{0}{r}$ & $\vec{\infty}$ & $\begin{array}{l}n \\
\infty\end{array}$ & 苂 \\
\hline 底 & $\stackrel{\infty}{\sigma}$ & $\overrightarrow{\mathrm{i}}$ & $\vec{R}$ & $\ddot{\infty}$ & $\overrightarrow{\widetilde{c}}$ & $\stackrel{0}{\infty}$ & $\vec{\infty}$ & ळे & $\begin{array}{l}\text { o. } \\
\text { in }\end{array}$ & $\begin{array}{l}\infty \\
i \\
\infty\end{array}$ & \\
\hline ن & $\begin{array}{l}0 \\
\stackrel{+}{t}\end{array}$ & $\stackrel{N}{N}$ & $\underset{\infty}{+\infty}$ & $\stackrel{n}{\infty}$ & $\hat{\infty}$ & $\begin{array}{l}+ \\
\infty \\
\infty\end{array}$ & $\begin{array}{l}+ \\
\text { Ni }\end{array}$ & $\stackrel{\infty}{\infty}$ & शे & $\tilde{\infty}$ & \\
\hline Ü & $\begin{array}{l}0 \\
\hat{\sim}\end{array}$ & $\begin{array}{c}0 \\
\hat{N}\end{array}$ & ஜֶ. & $\ddot{n}$ & "ू & त̂. & $\vec{n}$ & $\begin{array}{l}\infty \\
\underset{f}{f}\end{array}$ & $\begin{array}{l}0 \\
\dot{f}\end{array}$ & $\frac{9}{7}$ & . \\
\hline 党 & $\stackrel{2}{\Sigma}$ & $\underset{\infty}{\infty}$ & 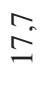 & $\underset{\sigma}{+}$ & $\ddot{\theta}_{0}^{\circ}$ & $\begin{array}{l}n \\
\infty\end{array}$ & $\hat{\sigma}$ & $\vec{i}$ & $\begin{array}{l}\dot{0} \\
\ddot{n}\end{array}$ & $\begin{array}{l}0 \\
\stackrel{n}{n}\end{array}$ & $\dot{4}$ \\
\hline$\sum_{U}$ & $\stackrel{0}{8}$ & $\overrightarrow{8}$ & กู & $\begin{array}{r}+ \\
i n\end{array}$ & $\stackrel{+}{i}$ & $\tilde{\tilde{n}}$ & $\begin{array}{l}\dot{v}_{0} \\
\text { in }\end{array}$ & $\begin{array}{l}\infty \\
\tilde{n}\end{array}$ & $\begin{array}{l}\text { ֶै } \\
\text { हn }\end{array}$ & $\begin{array}{l}n \\
0 \\
i\end{array}$ & \\
\hline 芯 & 2 & $\vec{a}$ & $\ddot{0}$ & $\stackrel{2}{2}$ & $\stackrel{0}{\infty}$ & $\stackrel{n}{0}$ & $\begin{array}{l}0 \\
0\end{array}$ & $\tilde{0}$ & $\begin{array}{l}\infty \\
\infty\end{array}$ & $\begin{array}{l}3 \\
\infty\end{array}$ & \\
\hline త్తే & $\vec{f}$ & $\overrightarrow{6}$ & $\begin{array}{l}0 \\
\ddot{\theta}\end{array}$ & $\hat{\sigma}$ & 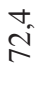 & $\stackrel{\circ}{\infty}$ & $\Rightarrow$ & $\stackrel{+}{\infty}$ & त̂ & $\vec{\infty}$ & 욜 \\
\hline ض் & ণ্ं & $\begin{array}{l}\infty \\
\underset{\sim}{\text { in }}\end{array}$ & $\overrightarrow{\vec{\lambda}}$ & $\ddot{\theta}$ & $\stackrel{n}{\sim}$ & $\begin{array}{l}0 \\
\text { ñ }\end{array}$ & $\begin{array}{l}0 \\
\text { b }\end{array}$ & बें & $\stackrel{n}{\mathcal{F}}$ & $\begin{array}{l}\infty \\
\stackrel{\gamma}{\gamma}\end{array}$ & $\begin{array}{l}50 \\
0 \\
\approx \\
\approx\end{array}$ \\
\hline 蓆 & in & $\begin{array}{l}\infty \\
i\end{array}$ & $\hat{n}$ & in & $n$ & $\begin{array}{l}0 \\
0\end{array}$ & $\begin{array}{l}0 \\
0\end{array}$ & $\underset{\sigma}{\sigma}$ & $\stackrel{\circ}{r}$ & $\stackrel{\circ}{\sim}$ & \\
\hline 婹 & $\tilde{\vartheta}$ & 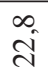 & 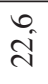 & $\frac{\infty}{i}$ & $\stackrel{+}{\stackrel{+}{d}}$ & $\begin{array}{l}0 \\
\text { in }\end{array}$ & $\overrightarrow{\hat{N}}$ & $\stackrel{m}{m}$ & $\begin{array}{l}0 \\
\dot{q}\end{array}$ & बें & \\
\hline 远 & $n$ & $\begin{array}{l}0 \\
\infty\end{array}$ & $\overrightarrow{8}$ & $\frac{0}{a}$ & สิ & $\begin{array}{l}\infty \\
\text { à }\end{array}$ & भे & ñ & $\begin{array}{l}\infty \\
\delta \\
\delta\end{array}$ & ลें & \\
\hline 空 & के & $\hat{\tilde{n}}$ & $\frac{n}{n}$ & 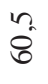 & $\overrightarrow{0}$ & $\frac{n}{6}$ & $\stackrel{\infty}{\infty}$ & $\overrightarrow{+}$ & $\stackrel{\circ}{i}$ & \begin{tabular}{l}
$\dot{I}$ \\
\multirow{I}{*}{}
\end{tabular} & \\
\hline 㓂 & $\begin{array}{l}\text { م } \\
\stackrel{\Xi}{=}\end{array}$ & $\begin{array}{l}\mathscr{\infty} \\
\varrho \\
\varrho\end{array}$ & \begin{tabular}{l}
$\infty$ \\
$\infty$ \\
\hdashline
\end{tabular} & ळ̄ & よ̆ & $\hat{\Omega}$ & ষ্ণ & ֻి & ¿্ণ & 홍 & \\
\hline
\end{tabular}


Figura 5

AFILIADOS AGRARIOS SOBRE EL TOTAL DE AFILIADOS A LA SEG. SOCIAL, AÑO 2011. (\%)

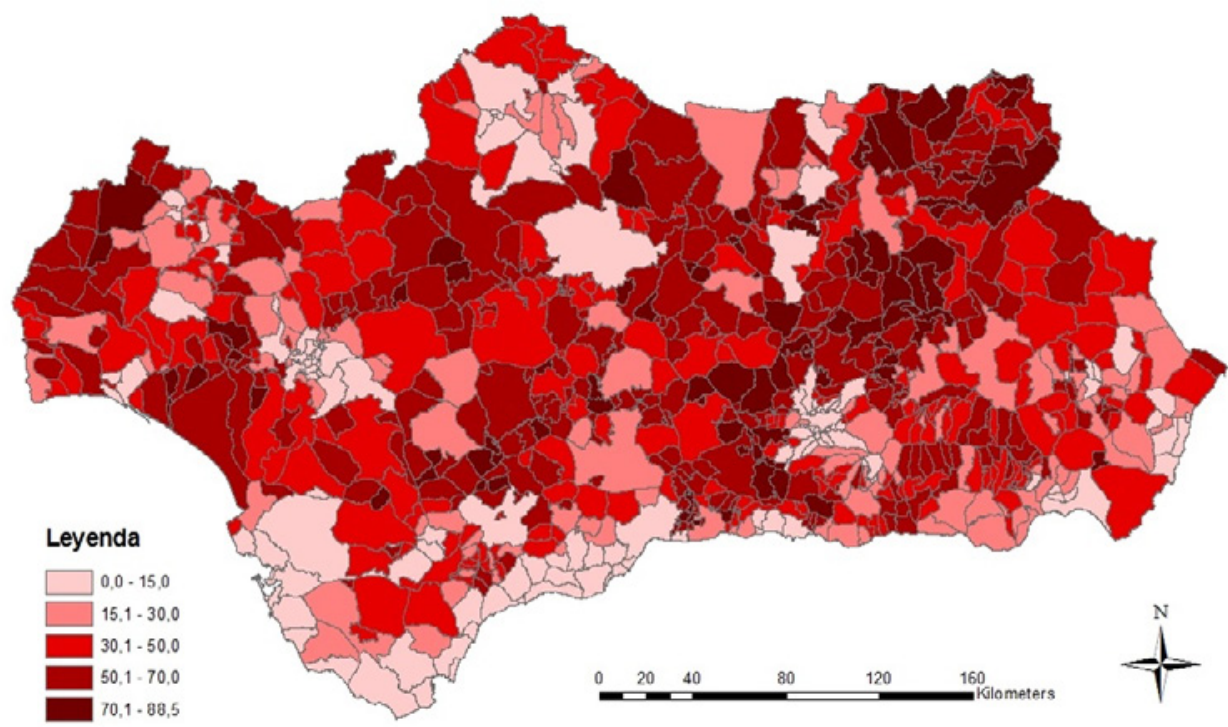

Fuente: Instituto de Estadística y Cartografía de Andalucía. Elaboración propia.

Figura 6

TEAS RESPECTO AL TOTAL DE AFILIADOS AGRARIOS, AÑO 2011. (\%)

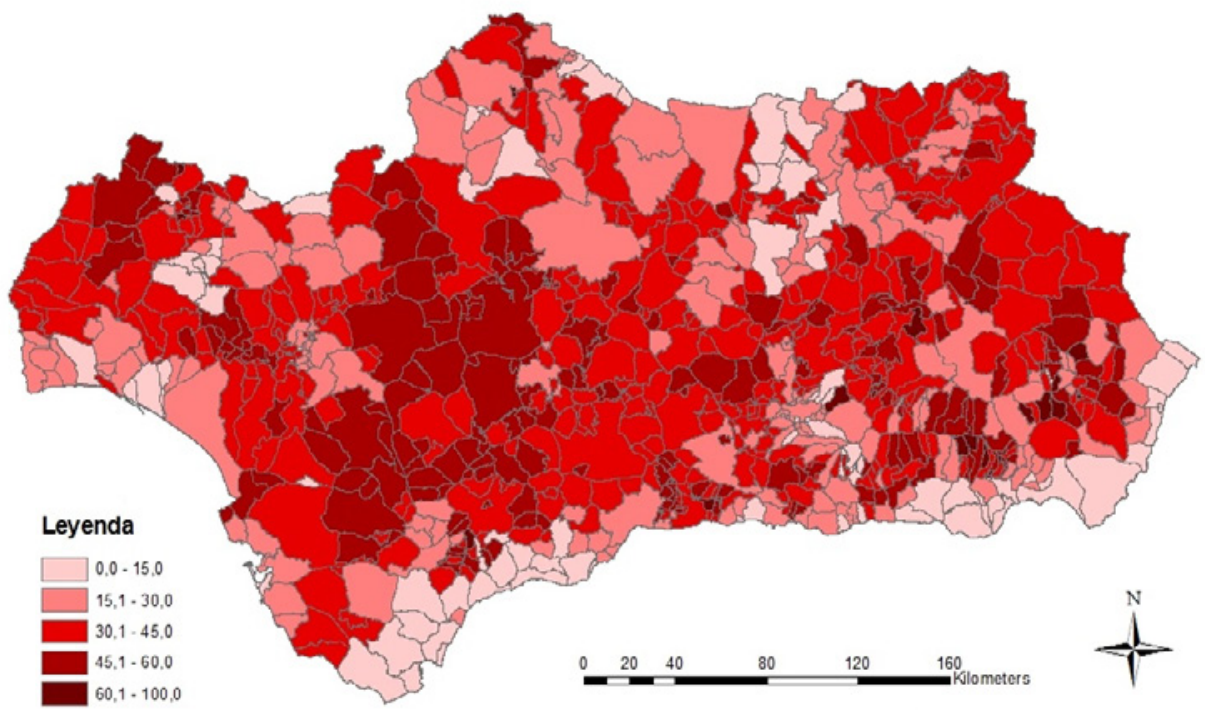

Fuente: Instituto de Estadística y Cartografía de Andalucía. Elaboración propia. 
cuando son superiores al 50\% en los intervalos superiores, de 1.000 a 5.000. Para estos municipios de menor tamaño, de 0-500, e incluso de 500-1.000, coincidentes a rasgos generales con el rural profundo montano de interior, el porcentaje de TEAS desciende y posee una menor representatividad, alcanzando para el primer intervalo apenas un 6,2\% respecto al grupo poblacional de 15-64 años. Además, son los intervalos de menor rango (0-500, 5001.000 y 1.000-2.000), los que han presentado mayores descensos porcentuales en el colectivo de TEAS respecto al grupo poblacional de 15-64 años entre 2000 y 2011, de en torno al $2,8 \%$. Parece, por tanto, que no se observa una correspondencia entre mayor ruralidad, mayor presencia de afiliados a la seguridad social agraria y mayor importancia del TEAS.

Ahora bien, cuando comparamos estos mapas con los obtenidos para el inicio del siglo -ver fig. 7- la realidad que observamos matiza, bastante, la anterior afirmación.

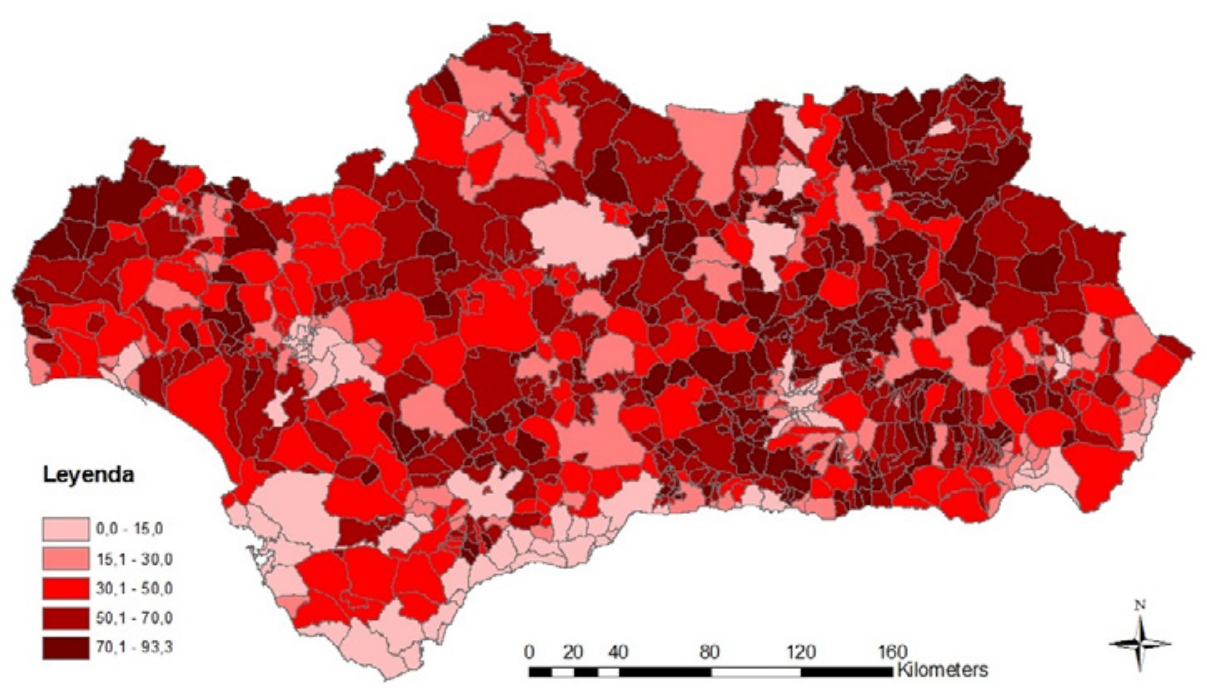

Fuente: Instituto de Estadística y Cartografía de Andalucía. Elaboración propia.

Lo primero que se observa es que son esos pequeños municipios, salpicados por ese rural profundo y serrano, los que alcanzan niveles de afiliación agraria superiores al $70 \%$. Municipios marcados por la presencia del olivar pero a los que se añaden otros no directamente ligados a él como la sierra onubense, la Alpujarra granadina y almeriense, parte de los altiplanos de Baza-Huéscar o de la Sierra Sur sevillana, incluso de la Axarquía malagueña. La segunda cuestión a tener en cuenta es que los porcentajes de TEAS respecto del de los afiliados agrarios representan menores valores en los municipios de menos de 2000 habitantes que en los comprendidos entre los 2.000 y 10.000 habitantes mientras que en 2011 son en los intervalos más pequeños en los que su importancia es mayor. Esta aparente contradicción creemos que tiene su explicación en el hecho de que los datos de afiliación proceden de enero de 2003, mientras los del TEAS son valores medios del año 2000. Si se tiene en 
cuenta que la reforma del 2002 limitaba los nuevos accesos al sistema, se provocó un efecto «llamada» que incrementó notablemente el volumen de afiliación en los años anteriores, lo que disminuye la ratio entre afiliados agrarios y TEAS. La secuencia que refleja dicha ratio en 2011 es mucho más real.

La evolución entre estas dos fechas viene marcada por el proceso de envejecimiento de las estructuras demográficas municipales, especialmente en los municipios con menores cifras poblacionales (26,9\% para 2011 en el intervalo de 0-500 hab.), y particularmente de sus activos agrarios, lo que los hace disponer de menores efectivos en este sector, y por tanto, de menores cifras en lo que respecta a TEAS; ello, probablemente ligado a una estructura agraria minifundista con cada vez menos necesidades de mano de obra. Por tanto, el envejecimiento de estos pequeños municipios y la ausencia de reemplazo laboral hacen que con el paso de los años tanto los afiliados agrarios como los TEAS se reduzcan a través de la jubilación, anticipada o no, de sus efectivos. Finalmente, habría que tener presente el despoblamiento de estos territorios o la «forzosa» diversificación de actividades para superar una agricultura de montaña poco rentable, la huida femenina y la consiguiente masculinización poblacional. Hay que recordar también, que la mayor parte de ellos se localizan en áreas de montaña de Jaén, Granada y Almería. Todo ello debe ser entendido en un contexto en el que la consideración productiva tradicional de la agricultura de montaña ha dado paso a su valoración multifuncional que, además, aporta a la sociedad otros bienes y servicios (sociales, patrimoniales, ambientales ) cada vez más demandados. Tales bienes y servicios tienen una gran relevancia para estas economías rurales por los recursos patrimoniales que generan y por su relación con la provisión de escenarios de ocio y esparcimiento muy valorados por el creciente y pujante turismo rural (Castillo y Cejudo, 2012).

\section{II.3. La tendencia del colectivo a la feminización y al envejecimiento}

La última cuestión a abordar es la feminización-envejecimiento del colectivo TEAS. La imposibilidad de nuevas incorporaciones al cobro del SDA a partir de la reforma de 2002, y la propia feminización explicarían este envejecimiento. La elevada presencia de mujeres en los TEAS es mayor conforme se avanza en el tiempo. Así, si para el año 2000, 59 de cada 100 eran mujeres, para 2011, son 65. También es mayor esta feminización conforme es mayor el tamaño poblacional de los municipios. Es más, estos dos procesos se visualizan de forma evidente entre las dos fechas que comparamos, las figuras 8 y 9 lo ejemplifican.

Ello conlleva que este subsidio se transforme en un ingreso complementario y continuo para la familia, además de proporcionar una jubilación digna para ellas. Territorialmente hablando, supone que los TEAS tendrán mayor significación dentro del colectivo de mujeres rurales, allí donde éstas, por una parte, no consigan un puesto de trabajo en otro sector, y por otra, donde aún no haya afectado sobremanera el éxodo rural en ellas, es decir, donde la representatividad de la mujer rural sea aún considerable. El no haber salido del sistema, bien por no poder, al estar inmersas en la «rueda del temporerismo, trabajando como temporeras durante las campañas agrícolas y percibiendo posteriormente el subsidio agrario» (Nuevo, 2000: 92), bien por no querer salir de éste, por la seguridad en los ingresos todo el año una vez cumplida la edad de 52 años, y el objetivo último de la obtención de una jubilación, están en el origen de este predominio femenino. 
Figura 8

PIRÁMIDE DEL TOTAL DE PERCEPTORES DE SDA, AÑO 2011

- HOMBRES IMUJERES

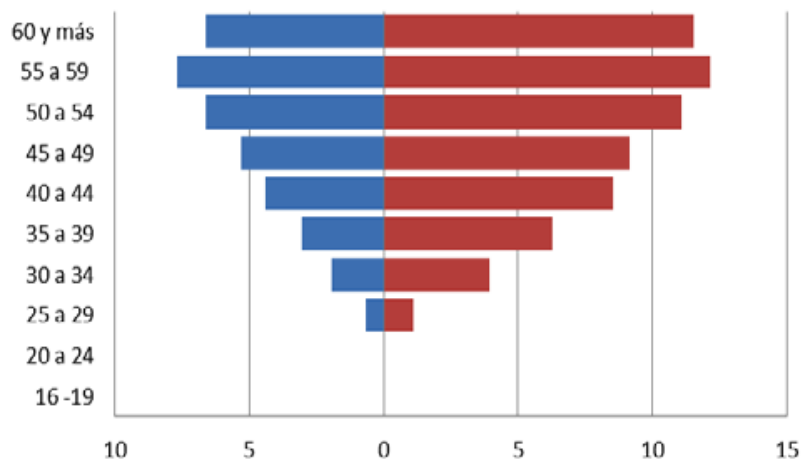

Fuente: Anuarios de Estadísticas Laborales del MTIN. Elaboración propia.

Figura 9

PIRÁMIDE DEL TOTAL DE PERCEPTORES DE SDA, AÑO 1996

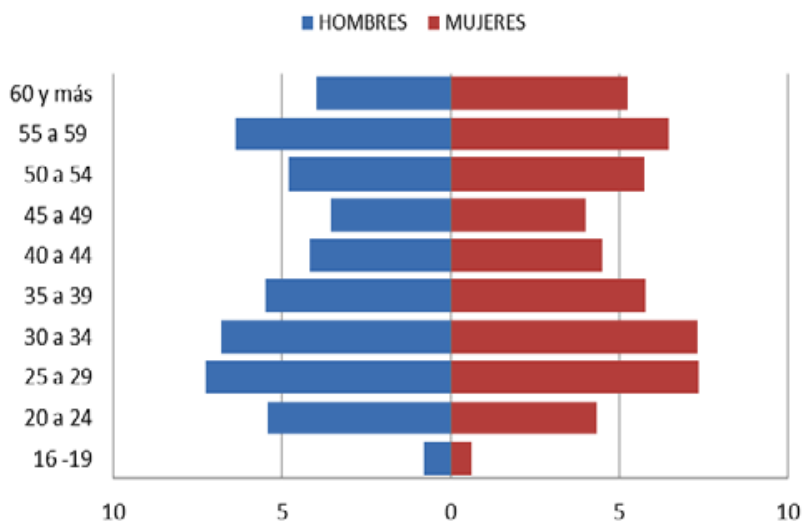

Fuente: Anuarios de Estadísticas Laborales del MTIN. Elaboración propia.

El comportamiento desde el punto de vista territorial varía y se intensifica con el paso de los años -ver figuras 10 y 11-. Por un lado, las zonas con mayores índices, por encima de 250 mujeres por cada 100 hombres, se encuentran en municipios integrantes de las Campiñas del Guadalquivir, de Sevilla y Córdoba, además de Huelva. Por otra parte, valores intermedios en este índice, entre 150 y 250, se sitúan en el área de la Subbética olivarera. Por último, también es notorio resaltar que la mayor parte de los valores inferiores de mujeres sobre hombres (menos de 100 féminas por número similar de varones), se encuentran en la mayor parte del rural profundo de montaña andaluz: Sierra Morena, desde Huelva hasta Jaén, y Cordillera Penibética, desde Cádiz hasta Almería. Esta distribución tiene explicacio- 
Figura 10

ÍNDICE DE FEMINIDAD DEL COLECTIVO DE TEAS, AÑO 2000

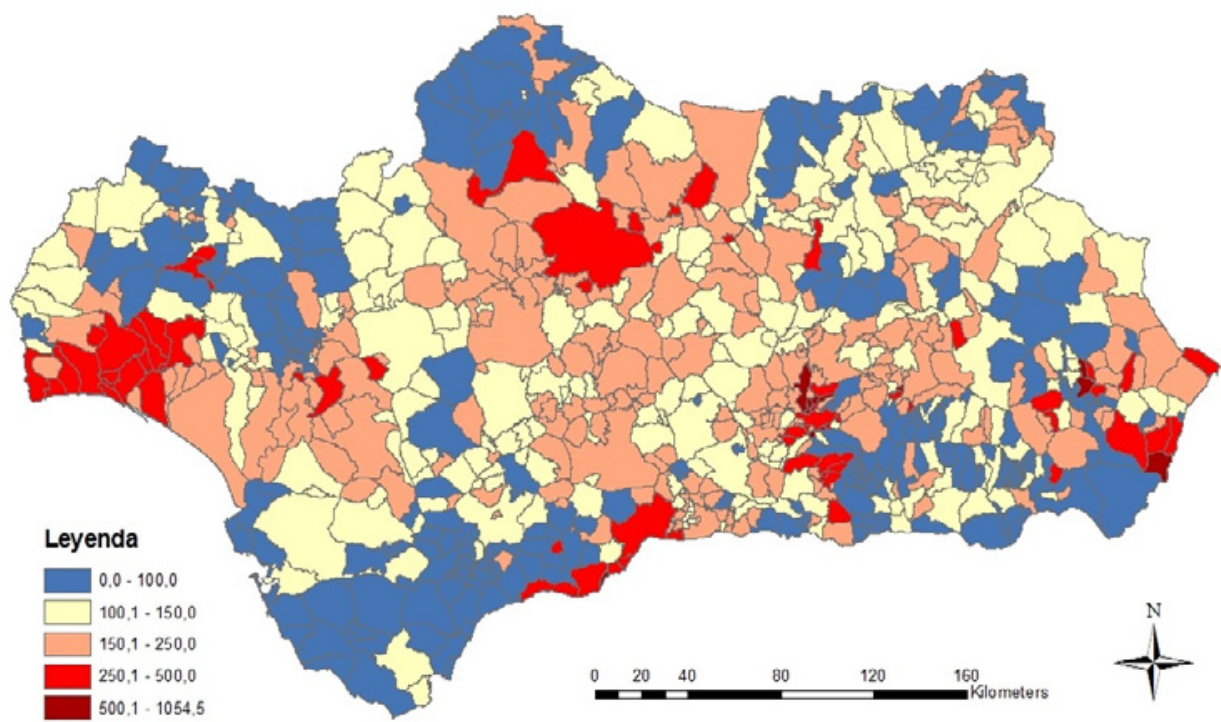

Fuente: Instituto de Estadística y Cartografía de Andalucía. Elaboración propia.

Figura 11

ÍNDICE DE FEMINIDAD DEL COLECTIVO DE TEAS, AÑO 2011

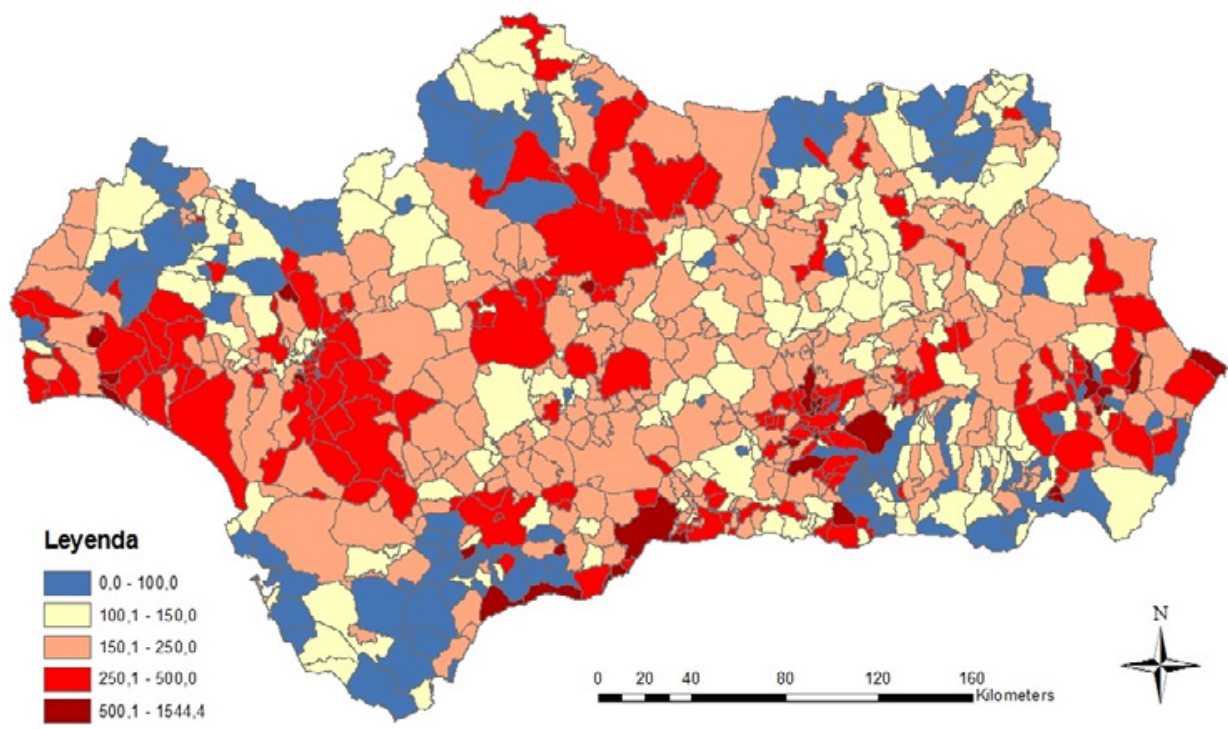

Fuente: Instituto de Estadística y Cartografía de Andalucía. Elaboración propia. 
nes dispares según los casos. En líneas generales tiene que ver, además de con los procesos de jubilación -que afectan al colectivo masculino antes que el femenino tanto por su mayor como anterior nivel de afiliación, en una histórica discriminación de género; con cuestiones productivas por su tradicional participación en ciertas actividades agrarias como el de la recogida de la fresa onubense; o al contrario, por el desarrollo de actividades en las que las mujeres tienen una significación muy pequeña, caso del sector ganadero -ya sea extensivo o intensivo- o forestal en zonas como la Sierra Morena jiennense, cordobesa u onubense o en las comarcas de la Sierra de Cádiz o de gran parte del Campo de Gibraltar. Todo ello sin menospreciar la importancia, imposible de contrastar en este trabajo, de la inclusión de mujer dentro del REASS cuando trabaja en tareas de manipulación y clasificación de producciones agrarias -hortaliza-, un sector fuertemente feminizado.

Esta mayor feminización de las Campiñas del Guadalquivir, se corrobora observando los valores absolutos de TEAS mujeres. Ellas, se encuentran, sobre todo en los municipios situados en la Campiña del Guadalquivir, de las provincias de Córdoba y Sevilla, y también, aunque en menor medida, en la Subbética olivarera. Y en el extremo opuesto, tanto en el litoral como el rural profundo montano apenas se encuentran cantidades absolutas importantes de féminas subsidiadas.

Lo anterior también se puede apreciar en el análisis por intervalos de población municipales -ver tabla 1-. Las féminas están más subsidiadas que los hombres, excepto para el caso de 0-500 y para el año 2000. Esta feminización es mayor conforme avanzamos en intervalos de población mayores: de 135,6 en el intervalo de 0-500, frente al de 225,3 en el intervalo de más de 20.000, para el año 2011. Acompañando lo anterior, hay que señalar también, que éstas, las mujeres integrantes del colectivo de TEAS, se encuentran con mayor representatividad dentro del total de efectivos demográficos femeninos de 15-64 años, en el rural intermedio, donde aún disponen de importantes cifras cuantitativas, donde aún no ha actuado sobremanera el éxodo rural femenino y dónde las dificultades de encontrar trabajo en otro sector son más fuertes al basarse su economía en el monocultivo del olivar. De hecho, en el intervalo situado entre 2.000-5.000, para el año 2000, representaban el 14,1\% de la población femenina comprendida entre 15-64 años, siendo para 2011, el 12,9\%. Al contrario, en el intervalo inferior, de $0-500$, para 2011, poseen casi similar importancia que para el intervalo de 10.000-20.000, apenas un 7,7\% de la población femenina de 15-64 años.

Finalmente, señalar el descenso de la importancia de las féminas en el grupo de población de 15-64 años a lo largo de los 11 años, aunque menor, si lo comparamos con el descenso total de TEAS respecto a este intervalo de población. Todavía sigue existiendo un elevado porcentaje de TEAS mujeres, por encima del 10\%, o incluso del $20 \%$, sobre todo en los municipios tanto de la Subbética olivarera, como de las Campiñas del Guadalquivir. Es decir, tal ayuda, supone un importante elemento de fijación de la población femenina en estos ámbitos, y de complementariedad con otros ingresos y tareas.

Indisolublemente unida a la tendencia de feminización en el colectivo de TEAS, está la de su envejecimiento. Las mujeres se incorporan a tal subsidio en una edad madura, y con su predominio, elevan la media de edad de los perceptores. La masiva percepción de la prestación a través del régimen especial para los mayores de 52 años, que no exige el criterio de cotización, explica que el colectivo cada vez se encuentre más envejecido y feminizado. Ello explicaría también su mayor localización en municipios olivareros de la Subbética y 
de la Campiña del Guadalquivir, donde las mujeres, ya de edad superior a los 50 años, que principalmente han dedicado su vida laboral a las tareas del hogar y otra serie de trabajos eventuales, acuden al SDA como forma de asegurar unas rentas mínimas, e incluso, su inmediata jubilación.

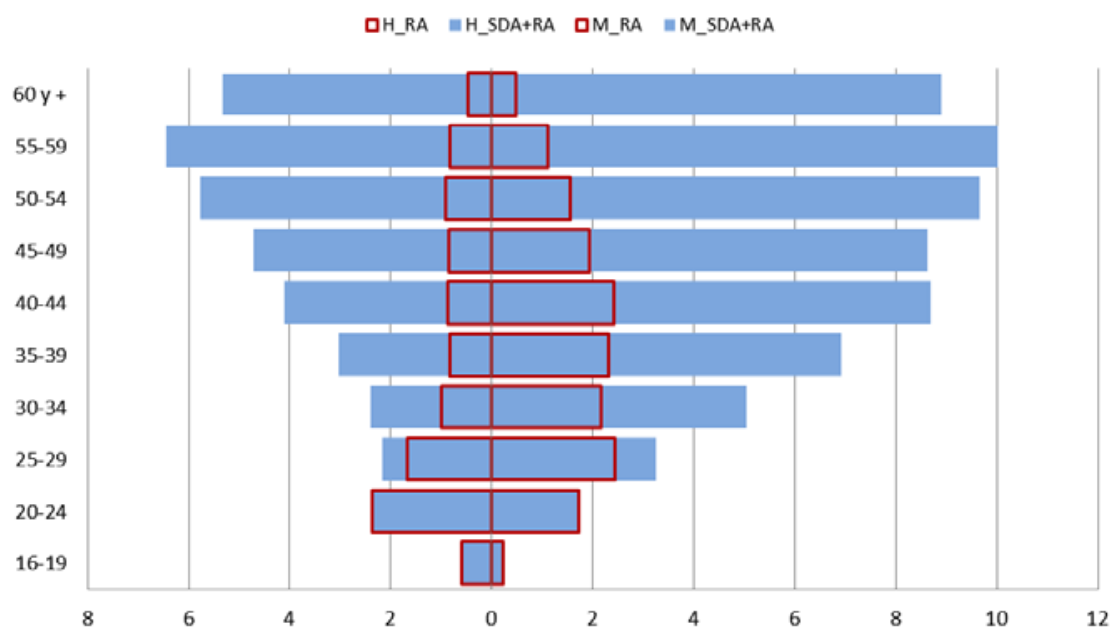

Fuente: Anuarios de Estadísticas Laborales del MTIN. Elaboración propia.

La excepción a lo anterior, sobre todo en lo que respecta a feminización y envejecimiento, son los recientemente incorporados perceptores de la RA -ver Figura 12-, donde los hombres, sobre todo los jóvenes (edad comprendida entre los 20 y 30 años, fundamentalmente), castigados fuertemente por la crisis de la construcción e industrias afines, se recluyen en este sector agrario como alternativa laboral, lo que conlleva también una importante incorporación de efectivos masculinos a este colectivo de TEAS. Aunque según Langreo y Requejo (2009: 363-364) «es poco probable que se reinserten en el sector agrario en condiciones similares a las existentes hace quince años». El reparto geográfico de éstos reafirma la distribución de los TEAS anteriormente señalado, por lo que no reproducimos el mapa correspondiente.

\section{A MODO DE CONCLUSIONES: CONSECUENCIAS DEL REPARTO SOCIO-TERRITORIAL DE LOS TEAS}

Tras haber expuesto las principales causas que explican la distribución del colectivo TEAS en la región andaluza, a continuación, es obligado señalar las principales consecuencias que se derivan de ello. Por supuesto, las implicaciones son complejas, positivas y negativas, directas e indirectas, y afectan a distintos ámbitos: territoriales, poblacionales, económicas, sociales, etc. 
El refuerzo del círculo vicioso del desempleo estructural. El SDA se convierte en parte del problema, en lugar de remedio. Siguiendo a Ramos y Romero (1995: 179), el SDA contribuye a reforzar el círculo vicioso del desempleo estructural en el mundo rural andaluz, donde los desempleados «son la mitad del año jornaleros (o mejor la sexta parte del año jornaleros) y la otra mitad subsidiados o el resto subsidiados agrarios». Y ello se aprecia con mayor virulencia en una serie de municipios de la Subbética olivarera, donde la preeminencia de este cultivo, la inexistencia de tareas a lo largo de gran parte del año (9 meses aproximadamente), contribuye a ese desempleo estructural. Ello da lugar a que la cultura del subsidio sea la predominante, y donde la dependencia de esta ayuda para un colectivo de personas sin apenas formación, sin perspectivas en otros sectores, sea vital. En cierta forma, el coste de mantener a esa población permanente se traslada al Estado, mientras que el empresariado agrario de la zona, se beneficia de tener una mano de obra de carácter eventual y con unas condiciones y exigencias laborales reducidas, con lo que ello conlleva de rémora en prestaciones sociolaborales, e incluso, en innovación y mecanización. No conviene olvidar que la pequeña propiedad, predominante en el olivar subbético, termina «anclando» al campesino al lugar lo que, unido al escaso tiempo de trabajo requerido en su explotación, propicia su empleo como jornalero que le permita completar sus ingresos familiares.

El sostenimiento de la dualidad en el agro, e incluso, en el territorio andaluz. Para el primero, la contraposición entre una agricultura intensiva, industrializada, mecanizada e innovadora, y que se nutre de una masa laboral inmigrante con precarias condiciones de trabajo, en el litoral andaluz (Costas de Almería y Huelva, principalmente), frente a una agricultura subsidiada interior (Molinero, Baraja y Alario, 2008), sobre todo en el caso del olivar (comarcas Subbéticas de Sevilla, Córdoba, Granada y Jaén, principalmente), que mantiene una mano de obra eventual con ayuda del SDA. Y en el segundo caso, una dualidad territorial marcada por la existencia de un litoral urbano-turístico, desarrollado, y un interior rural decadente y deprimido -salvo puntuales y exitosos ejemplos-, excesivamente dependiente de una agricultura subvencionada y subsidiada (SDA, pero también Política Agraria Comunitaria), tanto para el caso de la Subbética olivarera, como en menor medida, pero también, para el caso de las Campiñas del Guadalquivir. Se podría decir, que el SDA y la RA ayudan a establecer otra tipología de rural profundo para la región andaluza, con sus propios círculos viciosos, como el señalado anteriormente del desempleo estructural. Territorialmente también, la relevancia de estas prestaciones, especialmente del SDA, en relación con la población de los pequeños municipios rurales, que forman parte de ese rural profundo en la mayoría de los casos, reduce su importancia. Ello es debido a la salida del sistema de un volumen creciente de personas tras su jubilación lo que unido al envejecimiento de sus poblaciones y a la falta de relevo generacional en la actividad agraria de estos territorios, sin olvidar las limitaciones normativas impuestas en 2002 para nuevas incorporaciones al cobro de la prestación, terminan por reducir su importancia sobre unas poblaciones menguantes; a pesar de ello a la altura de 2011 el porcentaje de afiliados agrarios que a la vez eran TEAS en los municipios de menos de 2.000 habitantes era el más alto - un 40,4\% y 41,1\%, de 0-499 y de 500-999 hab., respectivamente-. La trascendencia de algunos procesos de diversificación económica y neorruralismo, escasos pero importantes, relativamente hablando, no debe ser menospreciada. 
Por último, e indirectamente también, la feminización del colectivo, contribuye a sostener unas estructuras sociales y laborales donde el hombre desempeña el papel principal, y donde la mujer queda relegada a trabajos secundarios, más precarios y eventuales, siempre subordinados a las tareas domésticas y del cuidado de la familia (progenitores y ancestros).

Por otra parte, también ayuda, en primer lugar, al mantenimiento de la estructura demográfica de los municipios rurales. Como se ha comprobado, tal SDA permite fijar población en el ámbito rural, frenando el éxodo rural, sobre todo en la Andalucía interior de media montaña correspondiente con el Subbético olivarero, aunque también, pero en menor medida, en las Campiñas del Guadalquivir. Además, la feminización de los perceptores, contribuye a mantener en los asentamientos rurales a la mayor parte de ellas, favoreciendo con ello, aunque de una forma reducida por la incorporación mayoritaria de éstas al SDA en edad no fértil, el reemplazo generacional en estas áreas rurales. Es decir, se fija población, ahora bien, mayoritariamente de edad adulta avanzada, la cual apenas ya incide en el crecimiento natural. También contribuye a mejorar la renta e ingresos familiares.

Además, el sostenimiento de la estructura poblacional. Ayuda a consolidar una estructura de asentamientos, que de otra forma, tenderían al abandono. El tejido poblacional de la Subbética olivarera, donde en sus comarcas, más del 10\%, alcanzando en algunas casi el 20\%, del colectivo de población entre 15-64 años es beneficiario de tal SDA. Tal estructura está basada en núcleos urbanos de 1.000-5.000 hab., excepcionalmente, entre 5.000-10.000. Pero también, aunque en menor medida, por su menor representatividad porcentual, contribuye a consolidar el tejido de ciudades medias y agrociudades de las campiñas del Guadalquivir. Con todo lo que ello conlleva de: mejor y más equilibrado reparto poblacional en el territorio; mejor cuidado del agro, contribuyendo a aminorar, entre otros problemas, la erosión del suelo o el riesgo de incendios; facilitando una mejor distribución de los servicios públicos en el territorio (sanidad, educación, ....); etcétera.

Y por último, la pervivencia de un elemento patrimonial y de un producto de calidad. Indirectamente, contribuye a mantener un cultivo social, un paisaje agrario tradicional, el olivar andaluz de media montaña, un patrimonio rural de gran valor (ambiental e históricamente, hablando), e incluso, en la elaboración de un producto de calidad y/o ecológico en algunas de estas comarcas olivareras (por ejemplo las denominaciones de origen del aceite de oliva de Sierra de Cazorla y Sierra de Segura, entre otras).

En síntesis, como se ha demostrado anteriormente, el SDA y la RA, tiene unas evidentes implicaciones geográficas al propiciar el mantenimiento del tejido poblacional y social de los espacios rurales andaluces. Los cambios que se están produciendo en estos territorios por su enorme importancia territorial, los colectivos implicados fuertemente feminizados, la edad de los mismos,..., nos apuntan hacia esta nueva finalidad que está cumpliendo esta prestación. Su importancia es vital para el mantenimiento demográfico y de los asentamientos del agro andaluz, sobre todo en ese rural con un desempleo estructural. La casi exacta coincidencia con la distribución de los afiliados a la seguridad social agraria, su concentración espacial a lo largo del tiempo, y la feminización-envejecimiento de su colectivo, posee una serie de consecuencias territoriales, complejas, y de todo tipo: directas e indirectas, positivas (sostenimiento demográfico y poblacional de gran parte de los ámbitos rurales del interior andaluz, contribución a la conservación del paisaje y el patrimonio rural, como principales), pero también negativas (mantenimiento del círculo vicioso del desempleo estructural, duali- 
dad del sector agrario y del territorio andaluz, sometimiento femenino, y apenas incidencia en las tasas reproductivas por ser mayoritariamente un colectivo de edad adulta avanzada, también como esenciales). Por tanto, el mantenimiento de este SDA y RA en el futuro ya no es únicamente una necesidad social, sino también territorial. Es vital para el mantenimiento demográfico y de los asentamientos del agro andaluz, especialmente los ligados al cultivo del olivar, los cuales, coinciden con los que poseen un desempleo estructural.

Ahora bien, los efectos negativos señalados, exigen que los planteamientos iniciales para conceder las prestaciones sean revisados profundamente (demográfica, económica, social y territorialmente), para tratar de evitarlos. Ampliar y facilitar su cobertura entre los trabajadores agrícolas del rural profundo montano; entre los colectivos desempleados de edad joven de ambos sexos para contribuir en mayor medida a la fijación poblacional y al reemplazo generacional; mejorar la formación y la cualificación de sus perceptores, principalmente de mujeres, tratando de integrarlas en otras ocupaciones del mercado de trabajo; la modernización del sector agrario, especialmente del subsector del olivar; el establecimiento de incentivos a la contratación de trabajo fijo para los empresarios agrarios, principalmente los olivareros (fiscalidad, tratamiento distinto en las cuotas, etc.); y la búsqueda de nuevos yacimientos de empleo en los territorios más afectados por el desempleo estructural rural; son alternativas estratégicas esenciales para evitar el círculo vicioso mencionado.

\section{BIBLIOGRAFÍA}

ANULA, C., DÍAZ, E. (1997): «Mercado de trabajo y estrategias familiares: el caso de la Andalucía rural». Estudios Regionales, $\mathrm{n}^{\circ}$ 48, 1-26.

ARNALTE, E., BAPTISTA, F.O., GARRABOU, R. (2012): «Viejas y nuevas dimensiones de la cuestión de la tierra». Revista Española de Estudios Agrosociales y Pesqueros, $\mathrm{n}$ 231, 11-28.

AVELLÁ, L., VEGA, V. (2002): «El mercado de trabajo agrario en la Comunidad Valenciana. Equilibrio global versus desequilibrios espaciales y temporales». Áreas. Revista Internacional de Ciencias Sociales, $\mathrm{n}^{\circ}$ 22, 95-112.

BAIGORRI, A. (Dir.) (1994): El paro agrario. Para, mercado de trabajo y formación ocupacional en el campo extremeño. Badajoz. Junta de Extremadura y Diputación Provincial de Badajoz.

BARCO, E. (2002): «Las manos que trabajan la tierra. Estudio sobre requerimientos de empleo en el sector agrario riojano». Cuadernos de Campo, $\mathrm{n}^{\circ} 22,4-17$.

CAMARERO, L. (Coord.) (2009): La población rural en España. De los desequilibrios a la sostenibilidad social. Barcelona. Obra Social de la Fundación La Caixa.

CANSINO, J.M., GÓMEZ, F. (1997) «Subsidio agrario y cotización de trabajadores eventuales: efectos sobre el mercado de trabajo agrario andaluz». Cuadernos de Estudios Empresariales, $\mathrm{n}^{\circ}$ 7, 177-188.

CANSINO, J.M. (Coord.) (2003): El campo andaluz y extremeño: la protección social agraria. Madrid. Consejo Económico y Social, Colección Estudios.

CASTILLO, J., CEJUDO, E. (2012): «Los espacios agrarios como construcción patrimonial: el patrimonio agrario» en Investigando en rural (García, A. et al., Coord.). Sevilla. Ulzama Ediciones, 349-358. 
CEJUDO, E., MAROTO, J.C., NAVARRO, F. (2013): «El Subsidio de Desempleo Agrario en Andalucía: de limosna de desmovilización campesina a ayuda territorial necesaria» en Desarrollo Regional Sostenible en tiempos de crisis (Camacho, J.A., Jiménez, Y., Eds.). Granada. Ed. Universidad de Granada, 709-738.

CORZO, S. (2002): El clientelismo político. El Plan de Empleo Rural en Andalucía: un estudio de caso. Granada. Universidad de Granada.

CRUCES, C., PALENZUELA, P. (2006). «Emprendedoras rurales en Andalucía. Posibilidades y límites de sus estrategias». Revista Española de Estudios Agrosociales y Pesqueros, $\mathrm{n}^{\mathrm{o}} 211,239-306$.

DELGADO, M. (1983): «Agricultura y Reforma Agraria en la economía andaluza». Nación Andaluza, no 2-3, 21-25.

DIAZ, J. (2009): «Los campos que otros trabajan. Las campañas agrícolas españolas con mayor porcentaje de trabajadores extranjeros», en Explorando los contratos en origen en los campos españoles (Gordo, M. y Felicidades, J., Eds.), Servicio de Publicaciones de la Universidad de Huelva, Huelva, 25-66.

DELGADO, M., GAVIRA, L. (2006): «Agricultura y trabajo rural en la globalización». Revista Española de Estudios Agrosociales y Pesqueros, $\mathrm{n}^{\circ}$ 211, 21-62.

ESCOBAR, M.S., GALERA, G., BERMÚDEZ, A. (2012): «La evolución del empleo agrario en Andalucía a partir del inicio de la crisis: ¿el fin del jornalero inmigrante?». VII Congreso sobre Migraciones internacionales en España. Bilbao del 11 al 13 de febrero, 2012. Disponible en http://congresomigraciones2012.com/memoria/.

FERNÁNDEZ-CAVADA, J.L., MARTÍN-FERNÁNDEZ, S., ORTUÑO-PÉREZ, S.F. (2007) «Evolución y perspectivas del mercado de trabajo agrario en España (1976-2004)». Agrociencia, $\mathrm{n}^{\circ} 41,241-251$.

GÁLVEZ, L., MATUS, M. (2012): «Género y ruralidad en Andalucía: un diagnóstico regional». Revista de Estudios Regionales, n ${ }^{\circ}$ 94, 195-218.

GARCÍA, M.D. y CRUZ, J. (1995): «Treball agrícola assalariat i gènere: le cas de les jornaleres andaluses». Documents d'Anàlisi Geogràfica, no 26, 109-121.

GARCÍA, J.I. (2004): Problemas de incentivos en el diseño de políticas asistenciales para la protección por desempleo: una aplicación al subsidio agrario. Disponible en http:// www.upo.es/econ/garcia/papers/per_october_2004.pdf.

GARCÍA, J.I., TRONCOSO, D. (2011): La introducción de la Renta Agraria: una evaluación del impacto sobre la oferta de trabajo en Andalucía y Extremadura. Working papers series. Department of Economics. Univ. Pablo Olavide. Disponible en http://www.upo. es/serv/bib/wps/econ1104.pdf.

GARCÍA, T. (2004): Mercado de trabajo en sistemas hortícolas intensivos: el caso de la fresa de Huelva. Tesis Doctoral. Universidad Politécnica de Madrid.

GAVIRA, L. (1992): «La estructura segmentada del mercado de trabajo rural en Andalucía». Revista de Estudios Regionales, ${ }^{\circ}$ 31, 87-104.

GÓMEZ, F., PRIETO, M. (2003): «Factores explicativos del diferencial del desempleo andaluz». Revista del Ministerio de Trabajo y Asuntos Sociales, $\mathrm{n}^{\circ}$ 46, 143-167.

GONZÁLEZ, J.A. (1997): El clientelismo político. Perspectiva antropológica. Barcelona. Anthropos Editorial. 
GUALDA, E. (2005) «La inmigración en Andalucía, de finales de los noventa a inicios del siglo XXI: tendencias de interés» en Integraciones diferenciadas: migraciones en Cataluña, Galicia y Andalucía (Solé, C., Izquierdo, A. coord.). Barcelona. Anthropos Editorial, 56-70.

JIMÉNEZ, J.D. et al. (2012): El comportamiento electoral en Andalucía: un análisis municipal. Documento de trabajo E2012/06. Sevilla. Centro de Estudios Andaluces. Disponible en http://centrodeestudiosandaluces.es/index.php?mod=publicaciones\&cat=1\&id=2678 \&ida $=0$ \&idm $=$

JOFRE-MONSENY, J. (2012). Do welfare benefits deter migration? . Disponible en: http:// www.ire.eco.usi.ch/paper-jofre-195491.pdf

LANGREO, A. (2002): «Mercado de trabajo y necesidades laborales en la agricultura española» en Procesos migratorios, economía y personas (Pimentel, M., ed.). Almería. Cajamar, 201-224.

LANGREO, A. (2004): «Mujer y trabajo en el mundo rural» en Mujeres, medio ambiente y desarrollo rural. (López, N. et al., Eds.). Madrid. Instituto Universitario de Estudios de la Mujer. 173-198.

LANGREO, A. y REQUEJO, J. (2009): «El regreso del trabajo agrario y rural como refugio» en Informe anual del sector agrario en Andalucía 2008. Málaga. Fundación UNICAJA, 349-364.

MÁRQUEZ, J. A. (Dir.) (2014): Jornaleros Extranjeros en España. Ei contingente agrícola de temporada como política de control de flujos migratorios. Servicio de Publicaciones de la Universidad de Huelva, Huelva.

MARTÍNEZ, J. (1978): «La actualidad de la Reforma Agraria». Agricultura y Sociedad, nº 7, 223-243.

MENDOZA, C. (2000): «Migración africana y agricultura en España: el caso de la provincia de Girona» en II Congreso sobre inmigración en España. Madrid. Universidad Pontificia de Comillas-Instituto Universitario de Estudios sobre Migraciones. 5-7 de octubre del 2000.

MARM (2011a). Condiciones de vida y posición social de las mujeres en el medio rural. Madrid. Dirección General de Desarrollo Sostenible del MARM. Disponible en www. magrama.gob.es /es/desarrollo-rural/temas/igualdad_genero_y_des_sostenible/condiciones_vida_tcm7-9725.pdf

MARM (2011b). Diagnóstico de la desigualdad de género en el medio rural. Madrid. Dirección General de Desarrollo Sostenible del MARM. Disponible en http://www. magrama.gob.es/gl/desarrollo-rural/temas/igualdad_genero_y_des_ sostenible/ DIAGN\%C3\%93STICO_COMPLETO_BAJA_tcm10-171812.pdf

MOLINERO, F., BARAJA, E., ALARIO, M. (2008): «Agricultura y transformación del espacio rural en España, 1986-2007» en España y el Mediterráneo. Una reflexión desde la Geografía española. (Aportación española al XXXI Congreso de la UGI de Túnez). Madrid. AGE. (formato CD).

MORENO, I. (1992): «Desarrollo del capitalismo agrario y mercado de trabajo en Andalucía». Revista de Estudios Regionales, n 31, 19-29.

NAREDO, J.M. (1971): La evolución de la agricultura en España. Desarrollo capitalista y crisis de las formas de producción tradicionales. Barcelona. Laia. 
NUEVO, T. (2000): «Las mujeres jóvenes en el medio rural; clave para el desarrollo». Estudios de Juventud, $\mathrm{n}^{\circ}$ 48, 91-96.

OBSERVATORIO DE EMPLEO AGRARIO ANDALUZ. (2004): Primer informe sobre el empleo agrario en Andalucía. Sevilla. Diputación de Sevilla.

OBSERVATORIO DE EMPLEO AGRARIO ANDALUZ. (2006): Segundo informe sobre el empleo agrario en Andalucía. Sevilla. Diputación de Sevilla.

OBSERVATORIO DE EMPLEO AGRARIO ANDALUZ. (2008): Tercer informe sobre el empleo agrario en Andalucía. Sevilla: Diputación de Sevilla.

PALENZUELA, P. (1989): Estrategias económicas domésticas de los jornaleros andaluces: salario, subsidio y economía sumergida. Agricultura y Sociedad, $\mathrm{n}^{\circ}$ 50, 75-107.

PITA, M.F., PEDREGAL, B. (Coord.) (2011). Tercer informe del desarrollo territorial de Andalucía 2010. Sevilla. Universidad de Sevilla.

PUMARES, P. (2006): «Efectos de la inmigración regularizada sobre el cambio en la estructura por regímenes y grupos de cotización de la Seguridad Social». Estudios Geográficos, $n^{\circ} 261,607-634$.

RAMOS, E., ROMERO, J. (1999): «Del «productivismo» al «ruralismo»: una reflexión sobre la política agraria en Andalucía». Revista de Estudios Agrosociales, n 169, 175-212.

ROBLES, A. (2003): «El clientelismo político y la democracia en Andalucía». Anuario de Derecho Parlamentario, ${ }^{\circ}$ 14, 223-239.

ROMÁN, R. (2004): «Cambios en el perfil del beneficiario el subsidio agrario (1984-2001)». Revista del Ministerio de Trabajo y Asuntos Sociales, n 51, 139-155.

ROMERO, J. (2009): La protección social agraria. Tesis Doctoral. Universidad de Granada.

SÁNCHEZ, A. (1980): «La eventualidad, rasgo básico del trabajo en una economía subordinada: el caso del campo andaluz». Sociología del Trabajo, nº 3-4, 97-198.

SÁNCHEZ, B., VICÉNS, J. (2010): «El impacto del subsidio agrario sobre la evolución de la población en Extremadura». Revista del Ministerio de Trabajo e Inmigración, $\mathrm{n}^{\circ}$ 86, 131-143.

SÁNCHEZ, P., GALLARDO, R. y CEÑA, F. (2014): «Rural áreas face economic crisis: Analyzing the determinants of successful territorial dynamic». Journal of Rural Studies, $\mathrm{n}^{\mathrm{o}} 35,11-25$.

SUMPSI, J.M. (1980): «Evolución tecnológica y racionalidad económica en las grandes explotaciones de la campiña andaluza» en A agricultura latifundiaria na Peninsula Iberica. (Barros, A. de. Coord.). Oeiras. Instituto Gulkeian de Ciencia, 303-341.

TALEGO, F. (2012): «La memoria y la tierra en el imaginario de los jornaleros andaluces» en Patrimonio cultural en la ruralidad andaluza. (Soler, S., Guerrero, C., Coord.). Sevi1la. Consejería de Cultura de la Junta de Andalucía, 64-79.

TORRES, T., ALLEZPU, R. y GORDO, M. (2013): «La contratación de mano de obra temporal en la agricultura hortícola española». AGER $\mathrm{n}^{\circ} 14,7-37$. 
